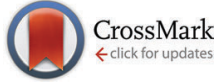

Cite this: J. Mater. Chem. C, 2015 3, 12245

Received 28th July 2015,

Accepted 30th October 2015

DOI: $10.1039 / c 5 t c 02318 a$

www.rsc.org/MaterialsC

\section{Crystal structure and thermoelectric properties of $\mathrm{Sr}-\mathrm{Mo}$ substituted $\mathrm{CaMnO}_{3}$ : a combined experimental and computational study $\dagger$}

\author{
D. Srivastava, ${ }^{a}$ F. Azough, ${ }^{a}$ R. Freer, ${ }^{* a}$ E. Combe, ${ }^{b}$ R. Funahashi, ${ }^{b}$ \\ D. M. Kepaptsoglou, ${ }^{c}$ Q. M. Ramasse, ${ }^{c}$ M. Molinari, d S. R. Yeandel, ${ }^{d}$ J. D. Baran ${ }^{d}$ \\ and S. C. Parker*d
}

\begin{abstract}
A combination of experimental and computational techniques has been employed to study doping effects in perovskite $\mathrm{CaMnO}_{3}$. High quality $\mathrm{Sr}-\mathrm{Mo}$ co-substituted $\mathrm{CaMnO}_{3}$ ceramics were prepared by the conventional mixed oxide route. Crystallographic data from X-ray and electron diffraction showed an orthorhombic to tetragonal symmetry change on increasing the Sr content, suggesting that Sr widens the transition temperature in $\mathrm{CaMnO}_{3}$ preventing phase transformation-cracking on cooling after sintering, enabling the fabrication of high density ceramics. Atomically resolved imaging and analysis showed a random distribution of $\mathrm{Sr}$ in the A-site of the perovskite structure and revealed a boundary

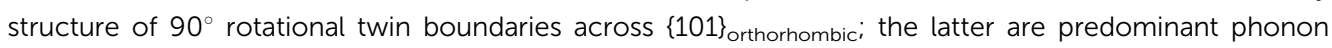
scattering sources to lower the thermal conductivity as suggested by molecular dynamics calculations. The effect of doping on the thermoelectric properties was evaluated. Increasing Sr substitution reduces the Seebeck coefficient but the power factor remains high due to improved densification by $\mathrm{Sr}$ substitution. Mo doping generates additional charge carriers due to the presence of $\mathrm{Mn}^{3+}$ in the $\mathrm{Mn}^{4+}$ matrix, reducing electrical resistivity. The major impact of $\mathrm{Sr}$ on thermoelectric behaviour is the reduction of the thermal conductivity as shown experimentally and by modelling. Strontium containing ceramics showed thermoelectric figure of merit $(Z T)$ values higher than 0.1 at temperatures above $850 \mathrm{~K}$. $\mathrm{Ca}_{0.7} \mathrm{Sr}_{0.3} \mathrm{Mn}_{0.96} \mathrm{Mo}_{0.04} \mathrm{O}_{3}$ ceramics exhibit enhanced properties with $\mathrm{S}_{1000 \mathrm{~K}}=-180 \mu \mathrm{V} \mathrm{K}^{-1}, \rho_{1000 \mathrm{~K}}=5 \times$ $10^{-5} \Omega \mathrm{m}, k_{1000 \mathrm{~K}}=1.8 \mathrm{~W} \mathrm{~m}^{-1} \mathrm{~K}^{-1}$ and $Z T \approx 0.11$ at $1000 \mathrm{~K}$.
\end{abstract}

\section{Introduction}

Thermoelectric materials are being engineered to improve the efficiency of generators that can produce electrical energy from waste heat. For over half a century, semiconductors such as Bi and $\mathrm{Pb}$ based tellurides have been used in niche applications. ${ }^{1}$ Thermoelectric oxide materials have attracted increasing attention in last two decades since the report of a high power factor in $\mathrm{NaCo}_{2} \mathrm{O}_{4} \cdot{ }^{2}$ Oxides offer distinct advantages of high temperature and chemical stability which opens a wide range of new applications. The efficiency of TE materials depends on the magnitude

\footnotetext{
${ }^{a}$ School of Materials, University of Manchester, Manchester, M13 9PL, UK. E-mail: Robert.Freer@manchester.ac.uk

${ }^{b}$ National Institute of Advanced Industrial Science and Technology, Midorigaoka, Ikeda, Osaka 563-8577, Japan

${ }^{c}$ SuperSTEM Laboratory, SciTech Daresbury Campus, Daresbury WA4 4AD, UK

${ }^{d}$ Department of Chemistry, University of Bath, Claverton Down, Bath BA2 7AY, UK. E-mail: S.C.Parker@bath.ac.uk

$\dagger$ Electronic supplementary information (ESI) available. See DOI: 10.1039/ c5tc02318a
}

of the dimensionless figure of merit $(Z T) ; Z T=S^{2} \sigma T / k$ where $S$ is the Seebeck coefficient, $\sigma$ the electrical conductivity, $T$ is the absolute temperature, and $k$ the thermal conductivity. Various cobaltites, including $\mathrm{Ca}_{3} \mathrm{Co}_{3} \mathrm{O}_{9}, \mathrm{Ca}_{2} \mathrm{Co}_{2} \mathrm{O}_{5}$ and $\mathrm{Bi}_{2} \mathrm{Sr}_{2} \mathrm{CoO}_{2}$ have already been reported with $Z T$ value as high as $1.2 .^{3-5}$ The perovskites $\mathrm{SrTiO}_{3}$ and $\mathrm{CaMnO}_{3}$, and also $\mathrm{ZnO}$ have been identified as promising n-type thermoelectric materials. ${ }^{6,7}$

$\mathrm{CaMnO}_{3}$ is an antiferromagnetic insulator at $300 \mathrm{~K}$ and stabilizes in the orthorhombic Pnma structure with unit cell parameters $\sim \sqrt{ } 2 a_{\mathrm{p}} \sim 2 a_{\mathrm{p}} \sim \sqrt{ } 2 a_{\mathrm{p}}$, where $a_{\mathrm{p}}$, is unit cell length of the ideal cubic perovskite. ${ }^{8,9}$ Using high-temperature X-ray diffractometry and thermal analysis Taguchi et al. ${ }^{10}$ reported the existence of two high temperature phase transitions from room temperature orthorhombic to tetragonal at $896{ }^{\circ} \mathrm{C}$ and from tetragonal to cubic symmetry at $913{ }^{\circ} \mathrm{C}$. Using in situ electron diffraction, Bocher et al. ${ }^{11}$ reported only one transition from orthorhombic to cubic on heating for $\mathrm{CaMn}_{0.98} \mathrm{Nb}_{0.02} \mathrm{O}_{3}$.

$\mathrm{CaMnO}_{3}$ possesses a relatively high Seebeck coefficient $\left(-250 \mu \mathrm{V} \mathrm{K}^{-1}\right)$, but the electrical conductivity, $\sigma$, is too low (10 to $100 \mathrm{~S} \mathrm{~m}^{-1}$ in the temperature range 300-1000 $\mathrm{K}$ ) 
resulting in a low power factor $\left(S^{2} \sigma\right)$ for the un-doped material. Un-doped $\mathrm{CaMnO}_{3}$ also shows a relatively high thermal conductivity of $3.5-2.5 \mathrm{~W} \mathrm{~m}^{-1} \mathrm{~K}^{-1}$ in the temperature range $300-1000 \mathrm{~K}$. The power factor of $\mathrm{CaMnO}_{3}$ has been enhanced by A-site substitution with different lanthanides. ${ }^{12-14}$ Similarly, an improved power factor has been achieved by B-site substitution with heterovalent cations including $\mathrm{Nb}, \mathrm{Ta}, \mathrm{W}, \mathrm{Ru}$ and $\mathrm{Mo}$ through introducing $\mathrm{Mn}^{3+}$ in the matrix. ${ }^{10,15-21}$ In a study of the effect of $\mathrm{Nb}$ and $\mathrm{Ta}, \mathrm{Xu}$ et al. ${ }^{15}$ reported a lower resistivity and Seebeck coefficient for $\mathrm{Nb}$ doping, achieving a $Z T$ of 0.08 at $1000 \mathrm{~K}$ for $\mathrm{CaMn}_{0.96} \mathrm{Nb}_{0.04} \mathrm{O}_{3}$. Later, Bocher et al. ${ }^{16}$ investigated the thermoelectric properties of $\mathrm{CaMn}_{1-x} \mathrm{Nb}_{x} \mathrm{O}_{3}(x \leq 0.08)$. They prepared the ceramics by both conventional mixed oxide and chemical routes; the reported TE data for the mixed oxide samples are in the same range as the data reported by $\mathrm{Xu}$ et $a .^{15}$ However, significantly improved TE properties were reported for the chemically prepared samples; the composition with $x=0.02$ showed a $Z T$ value of 0.2 at $900 \mathrm{~K}$, increasing sharply from 0.2 to 0.3 at $1000 \mathrm{~K}$. The main reason for the improved $Z T$ was the remarkable reduction of thermal conductivity of the chemically prepared samples to around $0.8 \mathrm{~W} \mathrm{~m}^{-1} \mathrm{~K}^{-1}$ in the measured temperature range compared to thermal conductivity values of $2.8 \mathrm{~W} \mathrm{~m} \mathrm{~m}^{-1} \mathrm{~K}^{-1}$ at $300 \mathrm{~K}$ to $1.5 \mathrm{~W} \mathrm{~m}^{-1} \mathrm{~K}^{-1}$ at $1000 \mathrm{~K}$ for the mixed oxide samples.

Miclau et al. ${ }^{17}$ showed that heterovalent doping by $\mathrm{W}$ at the B site leads to generation of $\mathrm{Mn}^{3+}$ in the matrix, resulting in the reduction of the electrical resistivity and Seebeck coefficient giving an overall improvement in the power factor. The effect of W substitution on the thermal conductivity was not reported.

Recently, Thiel et al. ${ }^{18}$ studied the system $\mathrm{CaMn}_{1-x} \mathrm{~W}_{x} \mathrm{O}_{3}$ $(x \leq 0.05)$, employing a chemical route similar to that used by Bocher et al. ${ }^{16}$ They found that $\mathrm{W}$ substitution increased the power factor with small reduction in the thermal conductivity achieving a $Z T$ of 0.15 at $1000 \mathrm{~K}$. The $Z T$ value further increased to 0.25 at $1225 \mathrm{~K}$. This increase in $Z T$ from $1200 \mathrm{~K}$ to $1225 \mathrm{~K}$ was reported to be due to the loss of oxygen and creation of oxygen vacancies. A reduction in $Z T$ above $1225 \mathrm{~K}$ was attributed to a phase transition from orthorhombic to cubic symmetry.

The effect of oxygen stoichiometry on the crystal structure has been investigated by several groups. Reller et $a .^{19,20}$ and Loshkareva et al. ${ }^{21}$ suggested that ordered super structures are formed by the introduction of oxygen vacancies. It was later shown that the application of tensile strain lowers the formation energy of oxygen vacancies selectively, depending on the lattice site, which prompted a possible new route to engineering vacancy ordering in epitaxial thin films. ${ }^{22}$ Ordering of oxygen vacancies was also found to strongly affect the thermoelectric properties of $\mathrm{CaMnO}_{3}$. Using ab initio calculations, Molinari et $a .^{23}$ found that partially reduced structures exhibited more favourable Seebeck coefficients compared to the highly reduced structures, while electrical resistivity was highly dependent on the vacancy ordering. However none of the simulated oxygen deficient structures showed enhanced power factor and $Z T$ values compared to stoichiometric $\mathrm{CaMnO}_{3}$. In parallel and independently, the computational observations of the effect of oxygen content by Molinari et $a l^{23}$ were confirmed experimentally by Schrade et al. ${ }^{24}$ They showed that oxygen deficiency reduced the absolute value of Seebeck coefficient and reduced the electrical conductivity.

Taguchi et al. ${ }^{25}$ showed that replacing up to $50 \%$ of the A site ions in $\mathrm{CaMnO}_{3}$ by $\mathrm{Sr}$ had a marked effect on the structure, the electrical resistivity (up to $973 \mathrm{~K}$ ) and Seebeck coefficient. Upon increasing the strontium content the lattice parameters increase, but there is no change in the orthorhombic symmetry; the $\mathrm{Mn}-\mathrm{O}-\mathrm{Mn}$ bond distances are independent of the Sr content but $\mathrm{Mn}-\mathrm{O}-\mathrm{Mn}$ bond angles increase with the increasing $\mathrm{Sr}$ content. Electrical resistivity increases with the $\mathrm{Sr}$ content, whereas the Seebeck coefficient decreases with increasing Sr. It was suggested that the changes in the transport properties are influenced by the $\mathrm{Mn}-\mathrm{O}-\mathrm{Mn}$ bond angles.

Recently, Pi et al. ${ }^{26}$ explored the effect of low levels of substitution of Mo for $\mathrm{Ca}$ on the thermoelectric properties of $\mathrm{CaMnO}_{3}$. They observed an increase in electrical conductivity and reduction in the Seebeck coefficient. For samples containing $4 \mathrm{~mol} \% \mathrm{Mo}$, i.e. $\mathrm{CaMn}_{0.96} \mathrm{Mo}_{0.04} \mathrm{O}_{3}$, the Seebeck coefficient was $-110 \mu \mathrm{V} \mathrm{K} \mathrm{K}^{-1}$, the thermal conductivity was $3.5 \mathrm{~W} \mathrm{~m}^{-1} \mathrm{~K}^{-1}$, and the $Z T$ was 0.01 at room temperature. Earlier, Maignan et al. ${ }^{27}$ studied the effect of higher levels (up to $15 \mathrm{~mol} \%$ ) of Mo substitution. They found the room temperature structure was orthorhombic up to $12 \mathrm{~mol} \%$, but transformed to monoclinic symmetry at higher levels of Mo. The room temperature electrical conductivity is $\approx 100 \mathrm{~S} \mathrm{~m}^{-1}$ for most compositions but the room temperature thermal conductivity is greatly influenced by Mo substitution, reducing from $2.8 \mathrm{~W} \mathrm{~m}^{-1} \mathrm{~K}^{-1}$ (7 mol\% Mo) to $1.4 \mathrm{~W} \mathrm{~m}^{-1} \mathrm{~K}^{-1}$ at $15 \mathrm{~mol} \% \mathrm{Mo}$.

For Sr-Mo co-doped $\mathrm{CaMnO}_{3}$, structural, microstructural and thermoelectric characterizations are mainly limited to low temperatures, up to $300 \mathrm{~K}$. Okuda and $\mathrm{Fujii}^{28}$ investigated the properties of $\mathrm{Ca}_{1-x} \mathrm{Sr}_{x} \mathrm{Mn}_{0.98} \mathrm{Mo}_{0.02} \mathrm{O}_{3}(x=0.00$ to 0.75$)$. They reported the structure to be orthorhombic (pnma) up to $x=0.5$, which transforms to tetragonal $(\mathrm{I} 4 / \mathrm{mcm})$ at $x=0.75$. In agreement with the work of Taguchi et al., ${ }^{25}$ Okuda and Fujii ${ }^{28}$ found that $\mathrm{Sr}$ substitution enlarges the $\mathrm{Mn}-\mathrm{O}-\mathrm{Mn}$ bond angle, which facilitates electron transfer of the electrons injected by the Mo substitution. Okuda and Fujii ${ }^{28}$ suggested that the combined effects of one electron transfer and disorder in the A-sites (caused by Sr substitution) increases electron transport which enhances the thermoelectric figure of merit. A thermoelectric figure of merit $Z T$ up to 0.03 was reported for $\mathrm{Ca}_{0.75} \mathrm{Sr}_{0.25} \mathrm{Mn}_{0.98} \mathrm{Mo}_{0.02} \mathrm{O}_{3}$ at room temperature.

Based on the promising low temperature thermoelectric properties of $\mathrm{Sr}$-Mo co-doped $\mathrm{CaMnO}_{3}$, we investigated the crystal structure, microstructure and high temperature thermoelectric properties of $\mathrm{Sr}-\mathrm{Mo}$ co-doped $\mathrm{CaMnO}_{3}$. Advanced electron microscopy in conjunction with atomistic calculations has been employed with a view to establishing correlations between structural characteristics and thermoelectric properties.

\section{Experimental methodology}

Ceramic samples of $\mathrm{Ca}_{(1-x)} \mathrm{Sr}_{x} \mathrm{Mn}_{(1-y)} \mathrm{Mo}_{y} \mathrm{O}_{3}$ with $x=0,0.1,0.3$, 0.6 and $y=0.02$ and 0.04 (listed in Table 1 ) were prepared by the conventional mixed oxide route. 
Table 1 Ceramic compositions

\begin{tabular}{lll}
\hline Number & Formulation & Sample code \\
\hline 1 & $\mathrm{CaMn}_{0.96} \mathrm{Mo}_{0.04} \mathrm{O}_{3}$ & CMM4 \\
2 & $\mathrm{Ca}_{0.9} \mathrm{Sr}_{0.1} \mathrm{Mn}_{0.98} \mathrm{Mo}_{0.02} \mathrm{O}_{3}$ & C9S1MM2 \\
3 & $\mathrm{Ca}_{0.9} \mathrm{Sr}_{0.1} \mathrm{Mn}_{0.96} \mathrm{Mo}_{0.04} \mathrm{O}_{3}$ & C9S1MM4 \\
4 & $\mathrm{Ca}_{0.7} \mathrm{Sr}_{0.3} \mathrm{Mn}_{0.96} \mathrm{Mo}_{0.04} \mathrm{O}_{3}$ & C7S3MM4 \\
5 & $\mathrm{Ca}_{0.4} \mathrm{Sr}_{0.6} \mathrm{Mn}_{0.96} \mathrm{Mo}_{0.04} \mathrm{O}_{3}$ & C4S6MM4
\end{tabular}

Starting materials were high purity powders of $\mathrm{CaCO}_{3}$ (Solvay, 99.5\%), $\mathrm{SrCO}_{3}$ (Solvay, 99.5\%), $\mathrm{MnO}_{2}$ (Sigma Aldrich, 99.9\%) and $\mathrm{MoO}_{3}$ (Sigma Aldrich, 99.9\%). $\mathrm{MnO}_{2}$ was wet milled for $24 \mathrm{~h}$ in a vibratory mill using zirconia balls and propan-2-ol in order to reduce the particle size. The powders were weighed in batches according to the required formulations and wet milled for $24 \mathrm{~h}$ in a vibratory mill using zirconia balls and propan-2-ol. The powders were then dried at $85{ }^{\circ} \mathrm{C}$ for $24 \mathrm{~h}$ and calcined twice at $1100{ }^{\circ} \mathrm{C}$ for $4 \mathrm{~h}$. The calcined powders were attrition milled using zirconia balls and distilled water for $8 \mathrm{~h}$ and then freeze dried. The powders were uniaxially compacted into pellets of $20 \mathrm{~mm}$ diameter and $5 \mathrm{~mm}$ thickness at a pressure of $50 \mathrm{MPa}$ prior to sintering at $1200-1450{ }^{\circ} \mathrm{C}$ for $4 \mathrm{~h}$ in air. Cooling rates of $6{ }^{\circ} \mathrm{C} \mathrm{h}^{-1}, 60{ }^{\circ} \mathrm{C} \mathrm{h}^{-1}, 180{ }^{\circ} \mathrm{C} \mathrm{h}^{-1}$, and $480{ }^{\circ} \mathrm{C} \mathrm{h}^{-1}$ were used.

Densification was assessed by the Archimedes method. Structural analysis was undertaken by X-ray diffraction using a Philips PW1830 system operating at $50 \mathrm{kV}$ and $40 \mathrm{~mA}$. The samples were first ground flat using 400 grade SiC and then scanned from $10-100^{\circ} 2 \theta$ in steps of $0.05^{\circ}$ with a dwell time of $20 \mathrm{~s}$ per step. Rietveld analysis of the data was undertaken using TOPAS $4.2 .^{29}$

The microstructures were examined by scanning electron microscopy (Philips XL30 FEGSEM equipped with EDX capability). The samples were ground using 240, 400, 800 and 1200 grade SiC and polished using $6 \mu \mathrm{m}$ and $1 \mu \mathrm{m}$ diamond paste. The final polishing stage employed an oxide polishing suspension (OPS).

The samples for TEM and STEM investigation were prepared by both ion beam thinning and crushing techniques. For ion beam-thinning, the specimens were first ground on 1200 grade $\mathrm{SiC}$ to reduce the thickness to $\sim 300 \mu \mathrm{m}$. They were ultrasonically cut into $3 \mathrm{~mm}$ diameter disks (Model KT150; Kerry Ultrasonic Ltd) and then dimpled (Model D500; VCR Group, San Francisco, CA) to reduce the thickness of the center of the disk to $30 \mu \mathrm{m}$. Finally, the disks were ion beam thinned (using a Gatan precision ion polishing system model 691; PIPSTM) operating at 4-6 kV. For the crushing method, the sintered disks were crushed to powders using an agate mortar and pestle. Grains of individual powders were dispersed in chloroform, dropped onto a copper grid with a holy carbon film, and then dried. The structures were initially investigated using selected area electron diffraction (SAED) and high-resolution transmission electron microscopy (HRTEM) techniques using a FEI FEGTEM (Tecnai G2, Hillsboro, OR) operating at $300 \mathrm{kV}$. Subsequently, atomic-resolution structural characterization was carried out using a dedicated aberrationcorrected Nion Scanning Transmission Electron Microscope (Nion UltraSTEM100, Nion Company, Kirkland, WA) located at the Daresbury SuperSTEM Laboratory in the United Kingdom.
The Seebeck coefficient and electrical conductivity were measured simultaneously using a ULVAC ZEM 3 in a helium atmosphere. Thermal conductivity was obtained by determining density (Archimedes method), thermal diffusivity (laser flash technique; facility built in house - argon atmosphere) and heat capacity (Netzsch STA 449C; nitrogen atmosphere); thermal conductivity was calculated from the product of all three parameters.

\section{Computational methodology}

DFT and potential based techniques were applied to a range of compositions $\mathrm{Ca}_{x} \mathrm{Sr}_{1-x} \mathrm{MnO}_{3}$. The formulations are listed in Table 2.

The DFT methodology was successfully used in our previous study on the effect of oxygen sub-stoichiometry on the thermoelectric properties of $\mathrm{CaMnO}_{3-\delta} \cdot{ }^{23,30}$ However, a brief summary is given here for completeness.

The structural models generated to determine the effect of $\mathrm{Sr}$ substitution on $\mathrm{Ca}$, comprised four $\mathrm{CaMnO}_{3}$ units with G-type antiferromagnetic order. Increasingly, $\mathrm{Ca}$, was substituted by aliovalent $\mathrm{Sr}$ to form compositions of $\mathrm{Ca}_{0.25} \mathrm{Sr}_{0.75} \mathrm{MnO}_{3}$, $\mathrm{Ca}_{0.5} \mathrm{Sr}_{0.5} \mathrm{MnO}_{3}$ and $\mathrm{Ca}_{0.75} \mathrm{Sr}_{0.25} \mathrm{MnO}_{3}$, to address the effect of Sr substitution on the thermoelectric properties.

The structural model generated to determine the effect of Mo substitution on $\mathrm{Mn}$, comprised $16 \mathrm{CaMnO}_{3}$ units with G-type antiferromagnetic order, which enabled simulation of $\mathrm{Ca}_{0.6875} \mathrm{Sr}_{0.3125} \mathrm{Mn}_{0.9375} \mathrm{Mo}_{0.0625} \mathrm{O}_{3}$. The optimized unit cell was a $2 \times 2 \times 2$ expansion of the Pnma $5.4116 \AA \times 7.6339 \AA \times 5.3952 \AA$ with $\alpha=\beta=\gamma=90$ degree cell.

A combination of planewaves and all-electron codes was used. For all models, geometry optimization was performed using spin-polarized generalized-gradient approximation (GGA) and the projector augmented wave (PAW) approach as implemented in the VASP code. ${ }^{31,32}$ The exchange correlation functional applied was the PBE with the inclusion of the Hubbard $U$ term using the Liechtenstein approach $(U=5 \mathrm{eV}$ and $J=1 \mathrm{eV})$. All calculations employed 3D boundary conditions, a cutoff energy for the planewave basis of $550 \mathrm{eV}$ and convergence criteria of $0.001 \mathrm{eV} \AA^{-1}$ on the forces for ionic relaxation and $10^{-8} \mathrm{eV}$ per atom for electronic relaxation. The Brillouin zone was sampled using $6 \times 6 \times 6$ and $2 \times 2 \times 2$ Monkhorst-Pack grids to ensure convergence for the $4 \mathrm{CaMnO}_{3}$ and $16 \mathrm{CaMnO}_{3}$ unit simulation cells, respectively. The electronic partial density of states (PDOS) for the $\mathrm{Ca}_{0.6875} \mathrm{Sr}_{0.3125} \mathrm{Mn}_{0.9375} \mathrm{Mo}_{0.0625} \mathrm{O}_{3}$ structure was evaluated using the GGA+U. The electronic structures for the $4 \mathrm{CaMnO}_{3}$ unit simulation cells were calculated using the

Table 2 Formulations for $a b$ initio calculations

\begin{tabular}{lll}
\hline Number & Formulations & Symbol \\
\hline 1 & $\mathrm{CaMnO}_{3}$ & $\mathrm{CMO}$ \\
2 & $\mathrm{Ca}_{0.75} \mathrm{Sr}_{0.25} \mathrm{MnO}_{3}$ & $\mathrm{C} 7.5 \mathrm{~S} 2.5 \mathrm{MO}$ \\
3 & $\mathrm{Ca}_{0.5} \mathrm{Sr}_{0.5} \mathrm{MnO}_{3}$ & $\mathrm{C} 5 \mathrm{MO} 5$ \\
4 & $\mathrm{Ca}_{0.25} \mathrm{Sr}_{0.75} \mathrm{MnO}_{3}$ & $\mathrm{C} 2.5 \mathrm{Sr} 7.5 \mathrm{MO}$ \\
5 & $\mathrm{CaMnO}_{2.75}$ & $\mathrm{CMO} 2.75 \mathrm{O}$ \\
6 & $\mathrm{CaMnO}_{2.5}$ & $\mathrm{CMO} 2.5 \mathrm{O}$ \\
7 & $\mathrm{Ca}_{0.6875} \mathrm{Sr}_{0.3125} \mathrm{Mn}_{0.9375} \mathrm{Mo}_{0.0625} \mathrm{O}_{3}$ & $\mathrm{C} 0.7 \mathrm{~S} 0.3 \mathrm{M} 0.9 \mathrm{M0} .1 \mathrm{O}$
\end{tabular}


full-potential linearized augmented plane wave besides the local orbitals (L/APW+lo) method as implemented in the WIEN2k code. $^{33,34}$ The muffin-tin radii were set to $2.18,2.09,1.84$ and 1.63 Bohr for $\mathrm{Sr}, \mathrm{Ca}, \mathrm{Mn}$ and $\mathrm{O}$, respectively, and the energy convergence criterion was set to $10^{-5}$ Ry. A mesh of 4896 $K$-points in the irreducible wedge of the Brillouin zone was chosen to generate high quality band structures. The electronic transport calculations were evaluated by solving the semi-classical Boltzmann transport equation within the constant relaxation time $(\tau)$ approximation as implemented in the BoltzTraP code. ${ }^{35}$ The choice of relaxation time was $0.5 \times 10^{-16} \mathrm{~s}$ as chosen by Molinari et $a l .{ }^{23}$ and successfully applied to other oxide thermoelectric materials. $^{36,37}$

Two methodologies were used to calculate the lattice component of the thermal conductivity ( $\left.k_{\text {lattice }}\right)$. In the case of DFT calculations of $\mathrm{CaMnO}_{3}$ systems, $k_{\text {lattice }}$ was evaluated for all the compositions within the $\mathrm{PBE}+\mathrm{U}$ using the Phono3py code. ${ }^{38-40}$

However, for the system containing the grain boundaries, due to the size of the system, potential based calculations were carried out using a potential model developed by Teter, ${ }^{41}$ based on partial charged rigid ions. The potential parameters employed are listed in Table 3.

Energy minimization employed the METADISE code; ${ }^{42}$ it shows that the potential model can reliably and accurately represent the experimental structure of $\mathrm{CaMnO}_{3}$ (Table 4). Generation ${ }^{43,44}$ of the domain boundary $\{101\}$, generally described as rotation twins across $\{101\}_{\text {orthorhombic }}$ was made by rotating one $\mathrm{CaO}$ terminated $\{101\}$ surface 180 degrees relative to a fixed surface. Energy convergence was tested and no variation was seen upon a three-fold increase of the number of species.

Molecular dynamics simulations were carried out using the LAMMPS code ${ }^{45}$ on a $10240 \mathrm{CaMnO}_{3}$ unit simulation cell $(146.99 \AA \times 59.87 \AA \times 59.89 \AA)$. Two systems were simulated; one consisting of a stoichiometric single crystal $\mathrm{CaMnO}_{3}$ and the other containing two domain boundaries spaced approximately $75 \AA$ apart. The domain boundaries were perpendicular to the $x$ direction and the boundary plane was in the $y z$ plane. The simulation cell was relaxed in the NPT ensemble at $500 \mathrm{~K}$ until the fluctuation of the volume was minimized and the lattice vectors were set to their average values. This was followed by a $20 \mathrm{~ns} N V T$ simulation at $500 \mathrm{~K}$ with a timestep

Table 3 Teter potential parameters, ${ }^{41} A_{\mathrm{ij}}, \rho_{\mathrm{ij}}$ and $C_{\mathrm{ij}}$, for the Buckingham form, $\varphi_{\mathrm{ij}}=A_{\mathrm{ij}} \exp \left(-r_{\mathrm{ij}} / \rho_{\mathrm{ij}}\right)-\left(C_{\mathrm{ij}} / r_{\mathrm{ij}}{ }^{6}\right)$ representing the interactions between ions in $\mathrm{CaMnO}_{3}$. Partial charges are associated with the atomic symbol

\begin{tabular}{lclc}
\hline Interactions & $A_{\mathrm{ij}}(\mathrm{eV})$ & $\rho_{\mathrm{ij}}(\AA)$ & $C_{\mathrm{ij}}\left(\mathrm{eV} \AA^{6}\right)$ \\
\hline $\mathrm{Ca}^{1.2+}-\mathrm{O}^{1.2-}$ & 7747.1834 & 0.252623 & 93.109 \\
$\mathrm{Mn}^{2.4+}-\mathrm{O}^{1.2-}$ & 73547.649 & 0.190091 & 226.25 \\
$\mathrm{O}^{1.2-}-\mathrm{O}^{1.2-}$ & 1844.7458 & 0.343645 & 192.58
\end{tabular}

Table 4 Experimental and simulation structural parameters

\begin{tabular}{|c|c|c|c|c|}
\hline & $a(\AA)$ & $b(\AA)$ & $c(\AA)$ & $\alpha=\beta=\gamma($ degree $)$ \\
\hline Exp. $(\text { Pnma })^{8}$ & 5.2816 & 7.4573 & 5.2675 & 90 \\
\hline Calc. (Pnma) & 5.2649 & 7.4589 & 5.2582 & 90 \\
\hline
\end{tabular}

of $1 \mathrm{fs}$ to calculate the thermal conductivity. The Green-Kubo ${ }^{46,47}$ method was used. The heat flux of the system was calculated at intervals of 10 timesteps over the $20 \mathrm{~ns}$ simulation and then correlated at each time interval and in each dimension. The correlations were integrated using the trapezoidal rule to yield thermal conductivities as a function of the integral length. A comprehensive estimation of the error is challenging ${ }^{48}$ and so we chose to calculate the error on the thermal conductivity from the size of the fluctuation of the integral. ${ }^{49}$

\section{Results and discussion}

\section{Physical properties}

The effect of particle size of starting powders and calcination processing was examined. It was found that by reducing the average particle size $\left(d_{50}\right)$ of the $\mathrm{MnO}_{2}$ starting powder to 1-2 $\mu \mathrm{m}$ and repeating the calcination step at $1100{ }^{\circ} \mathrm{C}$, a single phase perovskite could be obtained. This subsequently improved homogeneity of ceramics on sintering.

All the undoped $\mathrm{CaMnO}_{3}$ samples contained cracks when sintered to densities above $88 \%$. Crack-free samples with densities of at least $90 \%$ were obtained by substituting $\mathrm{Sr}$ for part of $\mathrm{Ca}$, replacing part of $\mathrm{Mn}$ by Mo and using a slow cooling rate of $180{ }^{\circ} \mathrm{C} \mathrm{h}^{-1}$ after sintering (sample densities: C9S1MM2 = 90\%, C9S1MM4 = 90\%, C7S3MM4 = 94\%, and C4S6MM4 = 93\%). Faster cooling rates than $180{ }^{\circ} \mathrm{C} \mathrm{h}^{-1}$ led to cracking; slower cooling rates led to no significant improvement in sample performance. Thus, $180{ }^{\circ} \mathrm{C} \mathrm{h}^{-1}$ was adopted as the standard cooling rate for all samples.

\section{Phase analysis}

Fig. 1 presents the X-ray diffraction spectra for all the formulations (Reitveld refinements of the spectra are provided in $\mathrm{ESI} \dagger$ ). All the spectra could be refined on the basis of a perovskite structure. With the exception of C4S6MM4, all the reflections can be indexed as orthorhombic perovskites, similar to that for un-doped $\mathrm{CaMnO}_{3}{ }^{7,8}$ with space group Pnma, where $a_{\text {orthorhombic }} \approx$ $c_{\text {orthorhombic }} \approx a_{\text {cubic }} \sqrt{2}$ and $b_{\text {orthorhombic }} \approx 2 a_{\text {cubic. }}$. The X-ray diffraction spectrum for C4S6MM4 can be refined in a tetragonal symmetry with $I 4 / \mathrm{mcm}$ space group, with $c_{\text {tetragonal }} \approx a_{\text {cubic }}$ and $c_{\text {tetragonal }} \approx a_{\text {cubic }}$. The observation of a change of symmetry upon increasing the Sr content is consistent with the findings of Okuda and Fujii. ${ }^{28}$ This change of room temperature symmetry from orthorhombic to tetragonal by substitution of Sr suggests that $\mathrm{Sr}$ widens the transition temperature window in $\mathrm{CaMnO}_{3}$ which is only $18{ }^{\circ} \mathrm{C}$ in the undoped end-member material. ${ }^{9}$ This widening of the temperature window for the symmetry change allows sufficient time (under conditions of slow cooling) for atomic rearrangement in the ceramic during cooling after sintering, thus preventing cracking. Hence, the incorporation of $\mathrm{Sr}$ doping effectively helps to modify the phase transformation temperature window, which with the controlled cooling rate, enables the preparation of dense, crack-free samples.

The XRD spectra show that individual peaks are displaced to lower values of 2 Theta as Sr substitution is increased, reflecting 


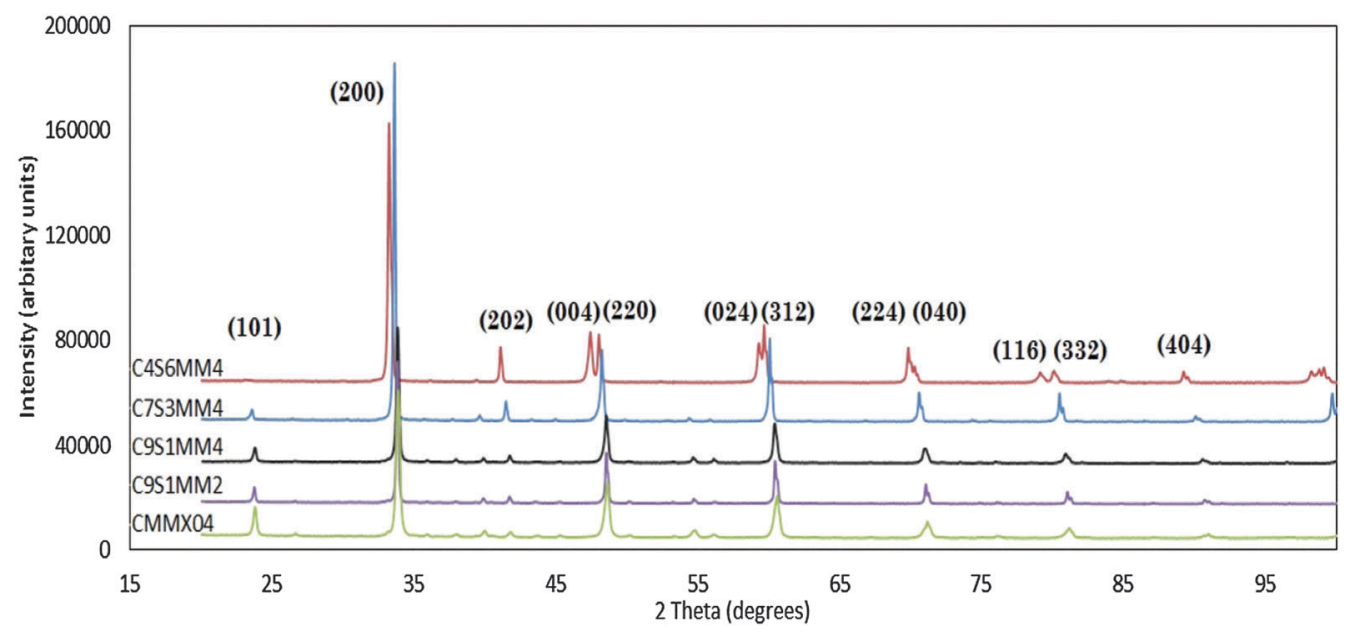

Fig. 1 Room temperature, $\mathrm{X}$-ray powder diffraction spectra of $\mathrm{Ca}_{1-x} \mathrm{Sr}_{x} \mathrm{Mn}_{1-y} \mathrm{Mo}_{y} \mathrm{O}_{3}$ ceramics.

the increase in lattice parameters as a result of substitution of species of higher ionic radii: $\mathrm{Sr}^{2+}(0.144 \mathrm{~nm})$ for $\mathrm{Ca}^{2+}(0.134 \mathrm{~nm})$ in cuboctahedral coordination and $\mathrm{Mo}^{6+}(0.059 \mathrm{~nm})$ for $\mathrm{Mn}^{4+}$ $(0.053 \mathrm{~nm})$ in octahedral coordination. The experimentallydetermined, refined structural parameters for all compositions are shown in Table 5; the residuals from the refinement
$\left(R_{\mathrm{wp}} / \mathrm{GOF}\right)$ are sufficiently small to have confidence in the data. For comparison purposes, the calculated structural parameters for selected $\mathrm{Ca}_{1-x} \mathrm{Sr}_{x} \mathrm{MnO}_{3}$ compositions, evaluated using ab initio techniques, are shown in Table 6.

The change of lattice parameters as a function of the $\mathrm{Sr}$ content for both experimental compositions and compositions

Table 5 Experimentally-determined, refined structural parameters for ceramics of $\mathrm{Ca}_{1-x} \mathrm{Sr}_{x} \mathrm{Mn}_{1-y} \mathrm{Mo}_{y} \mathrm{O}_{3}$ at room temperature

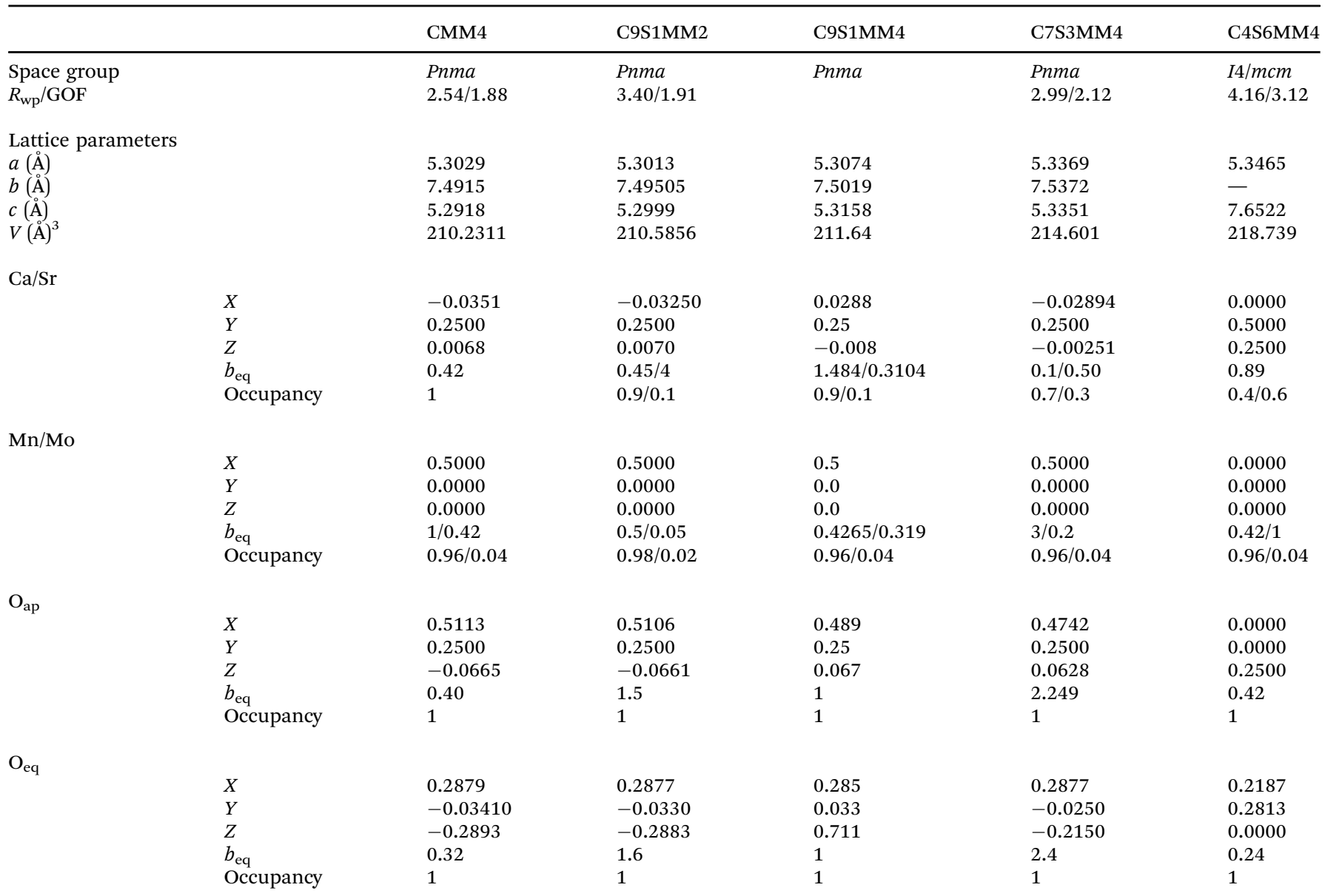


Table 6 Calculated structural parameters for different $\mathrm{Ca}_{1-x} \mathrm{Sr}_{x} \mathrm{MnO}_{3}$ compositions evaluated using ab initio techniques

\begin{tabular}{llllll}
\hline Phase & Symbol & $a(\AA)$ & $b(\AA)$ & $c(\AA)$ & $\alpha=\beta=\gamma$ (degree) \\
\hline $\mathrm{CaMnO}_{3}$ & CMO & 5.366 & 7.534 & 5.311 & 90 \\
$\mathrm{Ca}_{0.75} \mathrm{Sr}_{0.25} \mathrm{MnO}_{3}$ & C7.5S2.5MO & 5.378 & 7.589 & 5.361 & 90 \\
$\mathrm{Ca}_{0.5} \mathrm{Sr}_{0.5} \mathrm{MnO}_{3}$ & C5S5MO & 5.394 & 7.639 & 5.401 & 90 \\
$\mathrm{Ca}_{0.25} \mathrm{Sr}_{0.75} \mathrm{MnO}_{3}$ & C2.25S7.25MO & 5.417 & 7.665 & 5.440 & 90
\end{tabular}

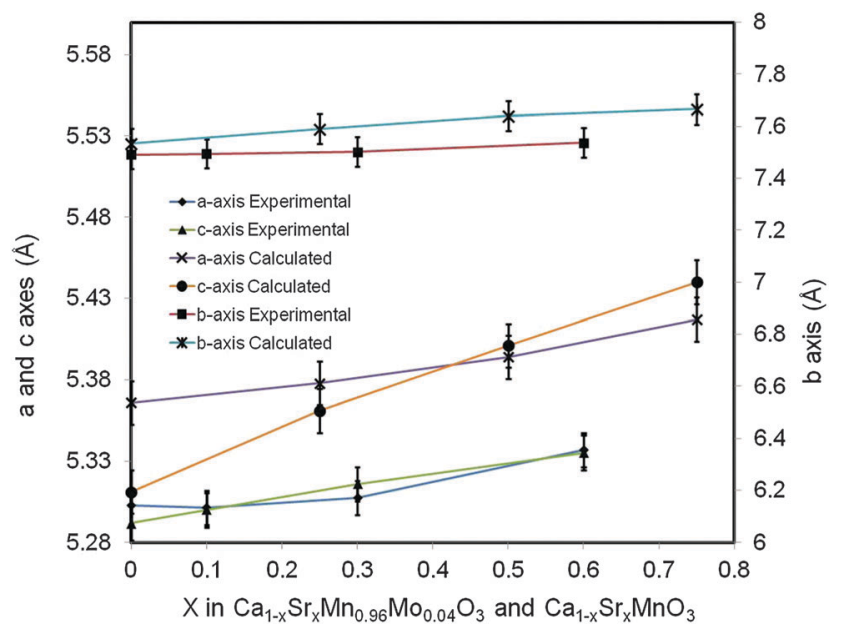

Fig. 2 Lattice parameters for $\mathrm{Ca}_{(1-x)} \mathrm{Sr}_{x} \mathrm{Mn}_{0.96} \mathrm{Mo}_{0.04} \mathrm{O}_{3}$, experimental compositions and $\mathrm{Ca}_{(1-x)} \mathrm{Sr}_{x} \mathrm{MnO}_{3}$ computational compositions as a function of the Sr content.

used in ab initio calculations is shown in Fig. 2. In both cases the lattice parameters increase with the increasing Sr content, in very good agreement with data reported by Taguchi $e t a l^{25}$ As highlighted above this is due to larger ionic radii of $\mathrm{Sr}^{2+}$ compared to that of $\mathrm{Ca}^{2+}$. The $a b$ initio lattice parameters are generally overestimated compared to the experimental values; this is a well know consequence of the methodology used (GGA+U).

\section{Electron microscopy}

The details of the microstructures were examined by SEM. Backscattered electron SEM images of C7S3MM4 and C4S6MM4 are shown in Fig. 3. The grains are equiaxed in shape with narrow grain size distributions; most individual grains are in the 5-10 $\mu \mathrm{m}$ range. Porosity is located at the grain boundaries and also trapped within the grains. For both compositions all the grains exhibit sub-grain boundaries arising from the transition from the high temperature cubic form to the low temperature orthorhombic or tetragonal form. ${ }^{9,10,28}$ An enlarged image of a grain of each composition (top left insets of Fig. 3a and b) shows details of the sub-grain boundaries. The morphology of the sub-grain boundaries is very different; for C7S3MM4 the boundaries are predominantly wavy in shape, whilst for C4S6MM4 the boundaries are straight. This is due to differences in their low temperature forms of symmetry - being orthorhombic for C7S3MM4 and tetragonal for C4S6MM4 (Table 1). In view of identification of significant differences in sub-grain features by SEM, more detailed microstructural investigations were undertaken by HRTEM and STEM-based electron energy loss spectroscopy (STEM-EELS).

TEM studies gave a better insight into the nature of the subgrain features observed in SEM. Fig. 4 illustrates a HRTEM image of the boundary which was frequently observed in C7S3MM4 ceramics. The Fourier Transform (FFT) for domain $\mathrm{A}$ and domain $\mathrm{B}$ and the twin boundary is shown in the figure. The FFT for both domains can be indexed as $\langle 101\rangle$ orthorhombic zone axes which are rotated at $90^{\circ}$ to each other to form the twin boundary. This type of twin boundary has been frequently observed in orthorhombic perovskites ${ }^{50,51}$ and is described as rotation twins across $\{101\}_{\text {orthorhombic }}$. As highlighted above, the features are symmetry-breaking transition induced boundaries. These sub-grain twin boundaries may contribute, by additional phonon scattering, to the low thermal conductivity of $\mathrm{CaMnO}_{3}$ compared to that of other perovskites such as $\mathrm{SrTiO}_{3} .{ }^{52}$

To further understand the materials, a detailed study of the distribution of $\mathrm{Sr}$ and $\mathrm{Ca}$ in the A-site, the structure of the twin boundary and the valance state of Mo, the samples C7S3MM4 and C4S6MM4 were examined by aberration corrected STEM at atomic resolution.

Fig. 5 shows the [010] atomic resolution and elemental chemical maps for ceramic C7S3MM4. The area used for elemental mapping is marked with a yellow square in Fig. 5a. The HAADF signal during the EELS acquisitions and maps of $\mathrm{Ca}, \mathrm{Sr}$ and $\mathrm{Mn}$ are presented in Fig. 5(b-e). These maps were generated by integrating the intensity of the $\mathrm{Ca}, \mathrm{Sr}$ and $\mathrm{Mn} \mathrm{L}_{2,3}$ edges over a $40 \mathrm{eV}$ window above the respective edge onsets, after subtraction of the decaying background using a power law model.
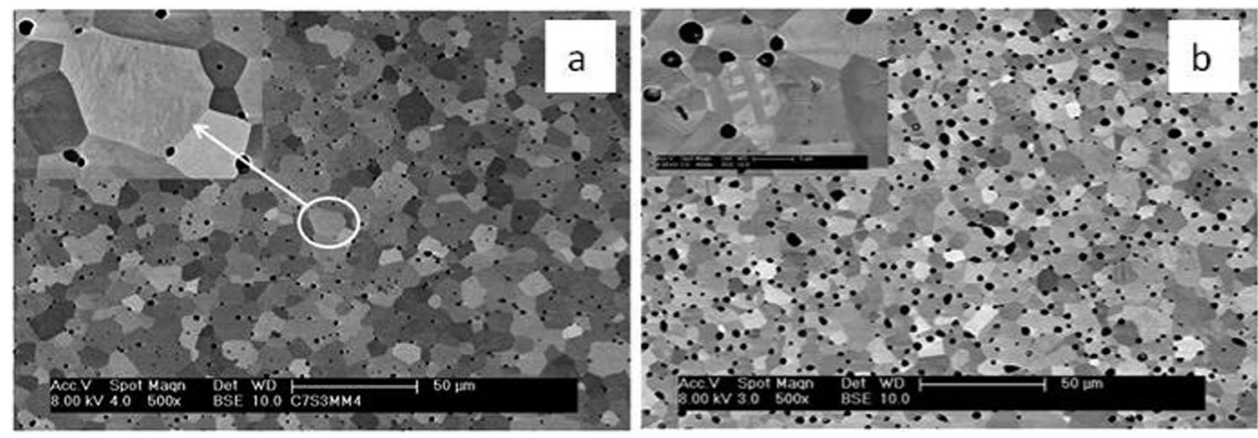

Fig. 3 Back scattered SEM images of C7S3MM4 and C4S6MM4. 


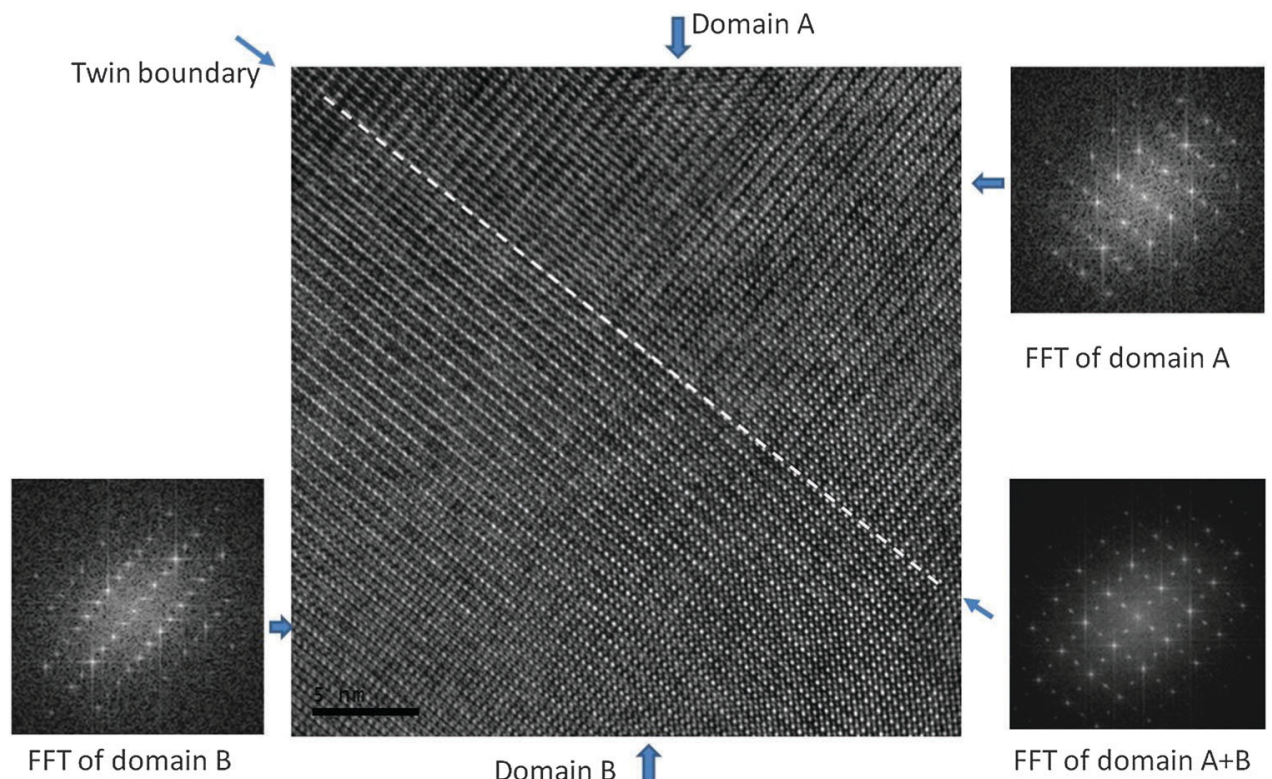

Fig. $4\{101\}$ HRTEM image of the twin domains A and B in C7S3MM4. On the top right and bottom left of the HRTEM image are the Fourier Transform (FFT) for domain A and domain B, respectively. The FFT from the twin boundary area is shown in the bottom right of the HRTEM image being a superposition of FFT in individual domains.
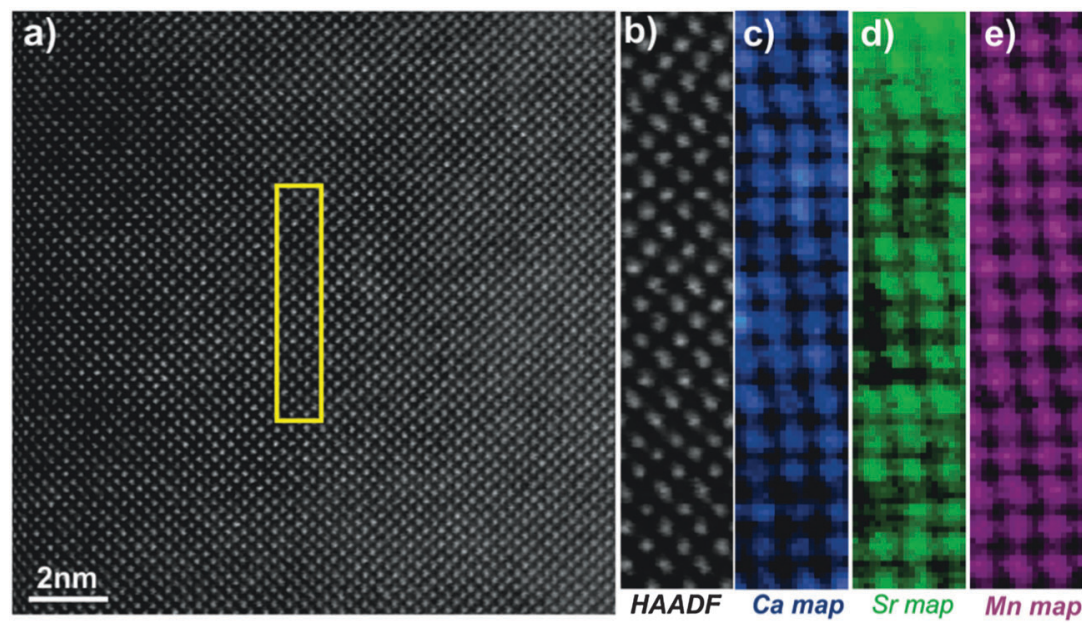

Fig. 5 [010] zone axis HAADF-EELS data for C7S3MM4. (a) HAADF image, (b) HAADF image acquired simultaneously during EELS data acquisition, (c) Ca EELS map, (d) Sr EELS map, (e) Mn EELS map.

The atomically resolved maps show the random distribution and absence of any ordering of Sr and Ca in the A-site of the perovskite structure. Similar data were collected for ceramic C4S6MM4 along the [001] orientation as shown in Fig. 6. It was found that $\mathrm{Ca} / \mathrm{Sr}$ distribution is also random for this formulation.

In order to observe the structure of the twin boundary and relate it to the thermoelectric properties, aberration-corrected high-angle annular-dark-field (HAADF) and bright field (BF) images were collected as shown in Fig. 7. The absence of any displacement of A-sites ( $\mathrm{Ca}$ and $\mathrm{Sr}$ ) or B-sites ( $\mathrm{Mn}$ and $\mathrm{Mo}$ ) columns in the HAADF images as shown in the enlarged section of Fig. $7 \mathrm{a}$ suggests that the different $\mathrm{BF}$ contrast is related to the change in the oxygen positions for the two [101] ortho and $[-101]_{\text {ortho }}$ planes.
The formation energy of the domain twin boundary was evaluated using energy minimization simulations; a very low value of $0.10 \mathrm{~J} \mathrm{~m}^{-2}$ was calculated. Thus, this bulk-like boundary is thermodynamically easy to form as it is formed by joining two bulk regions with oppositely oriented Mn octahedra. Contrary to experimental approaches and images, simulation techniques can identify the position of oxygen atoms (Fig. 8). To aid visualization of the twin boundary shown in Fig. 8, a black line, which also defines the $\{101\}$ surface, is drawn perpendicular to the [101] direction and represents the core of the grain boundary. This image supports the experimental finding (HAADF images) showing no displacements of A-site and B-site columns. The orthorhombic unit cell arises from rotation of the Mn octahedra, which causes them to rotate down or up. 

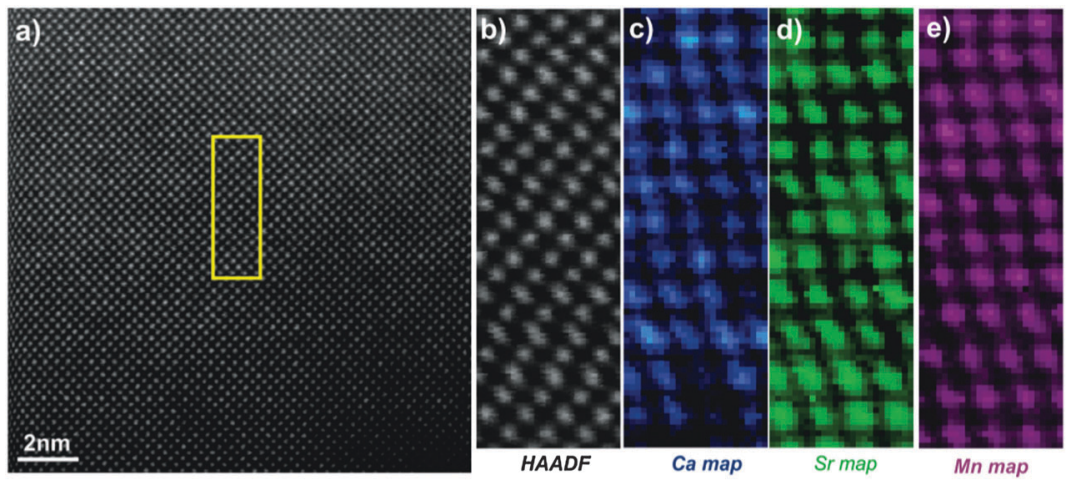

Fig. 6 [001] zone axis STEM-EELS data for C4S6MM4: (a) HAADF image, (b) HAADF image acquired simultaneously during EELS data acquisition, (c) Ca EELS map, (d) Sr EELS map, (e) Mn EELS map.

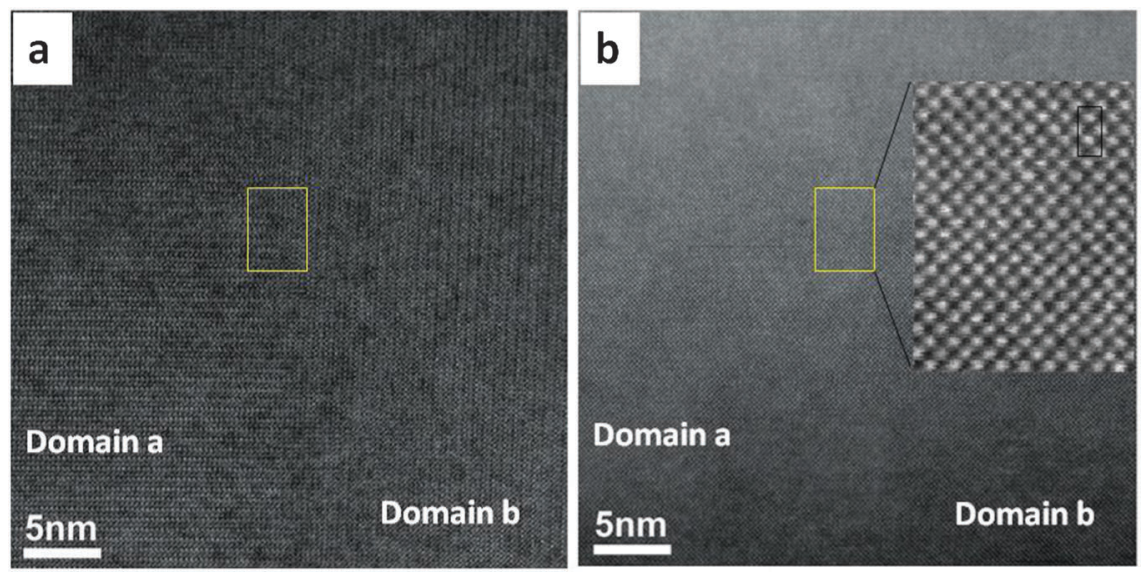

Fig. 7 (a) Aberration corrected bright field image (BF) STEM image of the twin boundary, (b) corresponding HAADF of the twin boundary, the enlarged HAADF image of a part of twin boundary is shown in the right side of the image. The rectangle in each figure represents the unit cell.

This can be easily viewed in terms of shape of the window of the A cation site in the [101] direction, which is diamond-shaped, arranged vertically (1) or horizontally (2) (Fig. 8(a)). Fig. 8(a) shows the domain boundary along the [101] direction and indicates that when the two surfaces $(\{101\}$ and $\{-101\})$ come into contact, the alternating pattern (1)-(2) cannot be imposed at the boundary region indicated by the double black arrow, and the Mn octahedra will have to rotate to accommodate the distortion, resulting in distorted windows (1)-(2) near the core of the grain boundary, where the windows are almost squared due to the Mn octahedra almost aligned (distorted (3)). Again to aid visualization, these diamond shaped windows are drawn in the figure; there are 3 distorted windows at the grain boundary that cannot be matched with the bulk like windows in black (1) and red (2). Fig. 8(b) represents the domain boundary along the [010] direction and reiterates the experimental findings indicating that the different BF contrast is related only to the change in the oxygen positions for the two $[101]_{\text {ortho }}$ and $[-101]_{\text {ortho }}$ planes. As shown in Fig. 8(c), which represents the surface $\{101\}$ along the [010] direction, the Mn octahedra form a repeating pattern up-down (UP-DN) whether or not they rotate in opposite directions. However, looking at the domain boundary orientated in the same [010] direction (Fig. 8(b)), this pattern is lost.
The relaxation of the $\mathrm{Mn}$ octahedra, due to the two joint surfaces, imposes a distortion for approximately $1 \mathrm{~nm}$ either side of the boundary core. This forces six Mn octahedra to retain the same orientation, 6 UP or 6 DN as shown in Fig. 8(b).

Substitution of Mo in the B-site will promote a mixed valance state for $\mathrm{Mn}$ according to $\mathrm{CaMn}_{1-3 x}{ }^{4+} \mathrm{Mn}_{2 x}{ }^{3+} \mathrm{Mo}_{x}{ }^{6+} \mathrm{O}_{3}$. Therefore, substitution of $x \mathrm{~mol} \%$ of Mo to the B-site will generate $2 x \mathrm{~mol} \%$ of $\mathrm{Mn}^{3+}$, which is $8 \mathrm{~mol} \% \mathrm{Mn}^{3+}$ for compositions with $4 \mathrm{~mol} \%$ substitution of Mo (i.e. composition CMM, C9S1MM4, C7S3MM4 and C4S6MM4). DFT calculations demonstrate the effect of Mo substitution by showing that the Fermi level is dominated by $\mathrm{Mn}^{3+}$ and $\mathrm{O}^{2-}$ states (Fig. 9), which appear only upon Mo substitution on $\mathrm{Mn}$ sites. The original composition $\left(\mathrm{Ca}_{0.6875} \mathrm{Sr}_{0.3125} \mathrm{Mn}_{0.9375} \mathrm{Mo}_{0.0625} \mathrm{O}_{3}\right)$ can therefore be rewritten as $\mathrm{Ca}_{0.6875} \mathrm{Sr}_{0.3125} \mathrm{Mn}_{0.8125}{ }^{4+} \mathrm{Mn}_{0.125}{ }^{3+} \mathrm{Mo}_{0.0625}{ }^{6+} \mathrm{O}_{3}$. Hence, the effect of Mo substitution is only to increase the concentration of electronic carriers, which in turn affects the thermoelectric properties of the material.

The EELS L edges of transition metals such as manganese result from the excitation of $2 p$ electrons into empty bound states or the continuum. Thus, these edges show two characteristic white lines, originating from transitions from the spin orbit split $2 \mathrm{p}_{3 / 2}$ and $2 \mathrm{p}_{1 / 2}$ levels to the available states in the $3 \mathrm{~d}$ band. 

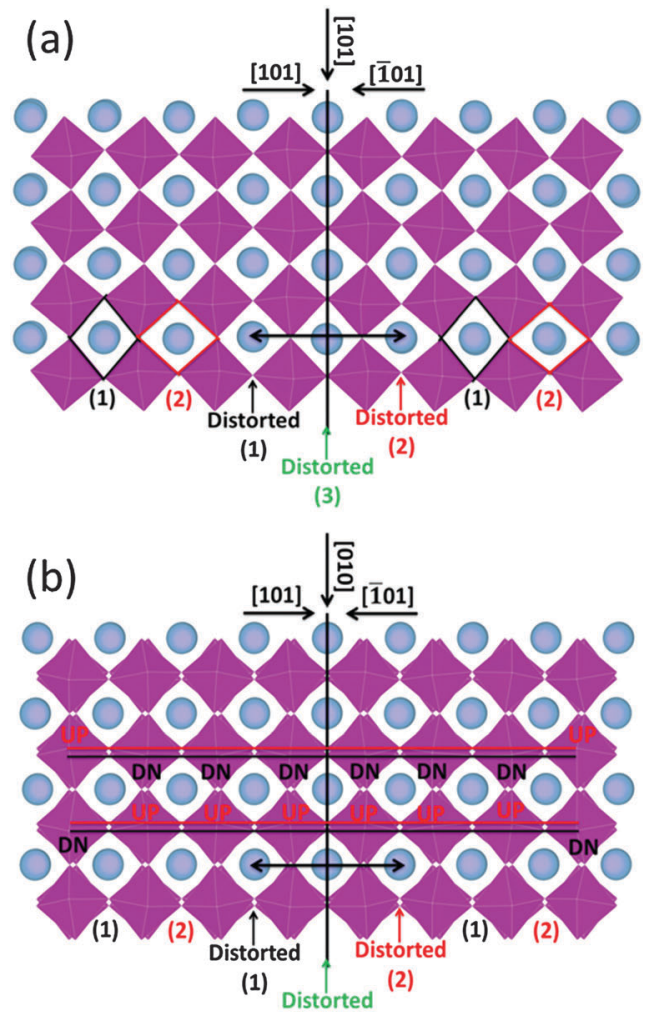

(3)

(c)

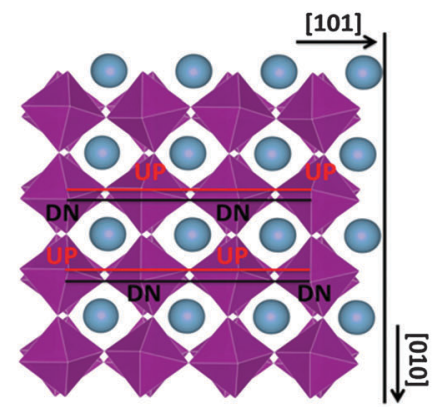

Fig. 8 Schematic representation of the domain twin boundary (a) along the [101] and (b) [010] directions, based on energy minimization calculations. For comparison (c) depicts the $\{101\}$ surface. Blue spheres are A-site cations and purple octahedra are B-site octahedra.

It has been shown that the intensity ratio of the $\mathrm{L}_{2}$ and $\mathrm{L}_{3}$ white lines is a characteristic of the oxidation state of manganese ions. ${ }^{53}$ Fig. 10 shows the $\mathrm{Mn}_{2,3}$ and $\mathrm{O} \mathrm{K}$ edges for ceramic C7S3MM4. Using the same type of curve-fitting analysis as used by Varela et $a .^{54}$ to obtain the valence state of $\mathrm{Mn}$ in $\mathrm{Ca}_{1-x} \mathrm{La}_{x} \mathrm{MnO}_{3}$, the white-line intensity for C7S3MM4 and C6S4MM4 was found to be $2.1 \pm 0.1$ and $2.0 \pm 0.1$, respectively. This suggests the Mn valence state to be close to $4+$ for both samples. ${ }^{53}$ Considering the $10 \%$ uncertainty in the data from this technique it is difficult to accurately define the $\mathrm{Mn}^{3+}$ content of the sample. However, electrical conductivity data which will be discussed later suggests the formation of $\mathrm{Mn}^{3+}$ due to Mo substitution in the B-site. Bocher et al. ${ }^{16}$ in an attempt to determine the $\mathrm{Mn}$ valence state in $\mathrm{Nb}$ doped $\mathrm{CaMnO}_{3}$ reported a small shift in the binding energy of the

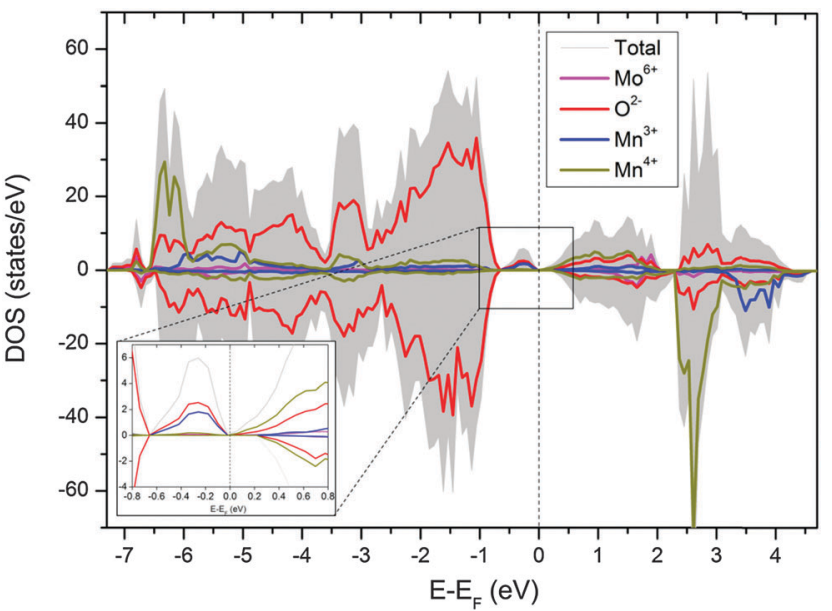

Fig. 9 Partial density of state of $\mathrm{CaMn}_{1-3 x}{ }^{4+} \mathrm{Mn}_{2 x}{ }^{3+} \mathrm{MO}_{x}{ }^{6+} \mathrm{O}_{3}$. The inset shows the states in the vicinity of the Fermi level.
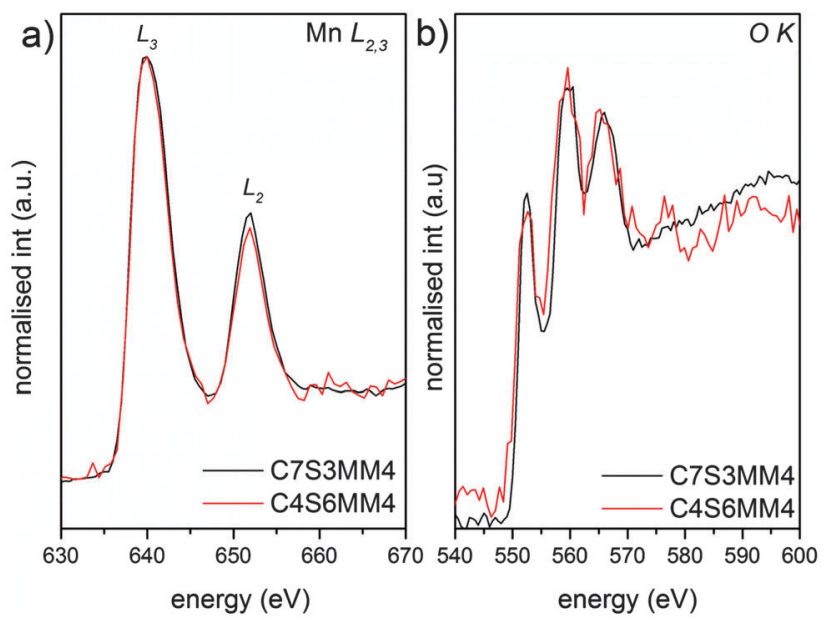

Fig. 10 Background subtracted (a) $M n L_{2,3}$ and (b) O K EELS spectra of C7S3MM4 (black) and C4S6MM4 (red) compositions.

$\mathrm{Mn}^{4+}$ oxidation state in $\mathrm{Nb}$ substituted $\mathrm{CaMnO}_{3}$ and suggested the formation of $\mathrm{Mn}^{3+}$. However, the reported values of the shift are too small, and the shift could equally well be due to a change in $\mathrm{Mn}^{4+}$ binding energy (resulting from a change of composition) as well as a change in the valence state of $\mathrm{Mn}$. Unfortunately, neither EELS nor XPS provide unambiguous data for these materials.

\section{Thermoelectric properties}

The resistivity data for the full set of experimental samples are presented in Fig. 11. Data for undoped $\mathrm{CaMnO}_{3}$, adopted from the work of $\mathrm{Xu}$ et $a .^{15}$ is shown in the inset of the figure. The resistivity values for the $\mathrm{Sr}-\mathrm{Mo}$ doped samples are in the range from $3.8 \times 10^{-4} \Omega \mathrm{m}$ to $5 \times 10^{-5} \Omega \mathrm{m}$ in the temperature window of measurement ( $300 \mathrm{~K}$ to $1000 \mathrm{~K}$ ). The resistivities for compositions C9S1MM4, C7S3MM4 are amongst the lowest values reported for B-site doped $\mathrm{CaMnO}_{3} \cdot{ }^{15,16}$ The substitution of $4 \mathrm{~mol} \%$ Mo for Mn (composition CMM4) reduces the resistivity by a factor of 3-4. This is due to the creation of additional 


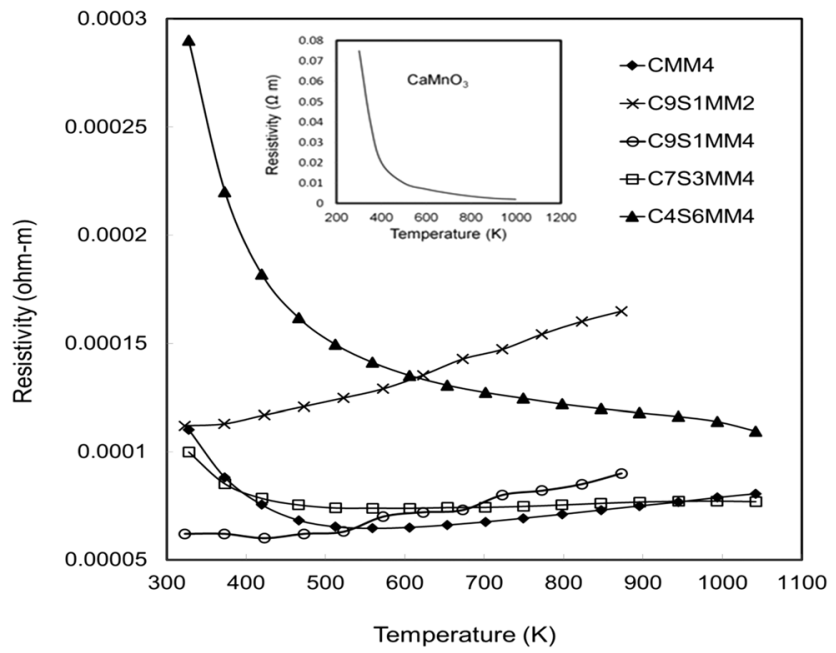

Fig. 11 Temperature dependence of the electrical resistivity of $\mathrm{Sr}-\mathrm{Mo}$ substituted $\mathrm{CaMnO}_{3}$. Data for undoped $\mathrm{CaMnO}_{3}$ is shown in the inset (adopted from Xu et al. ${ }^{15}$ ).

charge carriers due to the presence of $\mathrm{Mn}^{3+}$ in the $\mathrm{Mn}^{4+}$ matrix. ${ }^{13}$ The CMM4 sample shows a metallic behaviour above $400 \mathrm{~K}$ with values of approximately $1 \times 10^{-4} \Omega \mathrm{m}$ in the temperature range $400-1000 \mathrm{~K}$. The resistivity values and behaviour of compositions C9S1MM4 and C3S7MM4 are similar to that of CMM4. The composition with the highest Sr content, C4S6MM4 showed the highest resistivity at lower temperatures with semi-conducting behaviour. This increase in the resistivity for C4S6MM4 is due to the disordered distribution of $\mathrm{Sr}$ and $\mathrm{Ca}$ in the A-sites (as shown in the electron microscopy section) reducing charge mobility. Nevertheless, the low resistivity of C9S1MM4 and C7S3MM4 was aided by high density and Mo content. It was not possible to prepare high density, crack-free samples of CMM4.

As the experimentally determined resistivity data suggested a broadly intrinsic behaviour, with samples exhibiting either semiconducting or metallic characteristics, we have performed DFT calculations on simple systems to decouple the effect of co-doping (with Mo and Sr) on the resistivity. As the calculated resistivity values are obtained with respect to the relaxation time, which is an unknown parameter, we present the percentage change in resistivity with respect to C7.5S2.5MO (Fig. 12), which showed the highest resistivity at room temperature. All the data for computational samples show a semiconducting behaviour with the resistivity decreasing with increasing temperature. Indeed, the resistivity at high temperature is similar for all compositions, while intermediate Sr doping gives the lowest resistivity at low temperature. It is more likely, however, that the resistivity will not be strongly affected by aliovalent $\mathrm{Sr}$ substitution. Instead, we infer that the microstructure and reduction of $\mathrm{Mn}$ ions will be the more likely cause of this complicated behaviour. In our previous work, ${ }^{23}$ we have indeed shown that higher concentrations of $\mathrm{Mn}^{3+}$ decrease the resistivity, but this interpretation is not straightforward as the behaviour is strongly influenced by the arrangement of oxygen vacancies $\left(V_{\mathrm{o}}\right)$ (in line with the discussion in Loshkareva et $a l^{55}$ ), which are

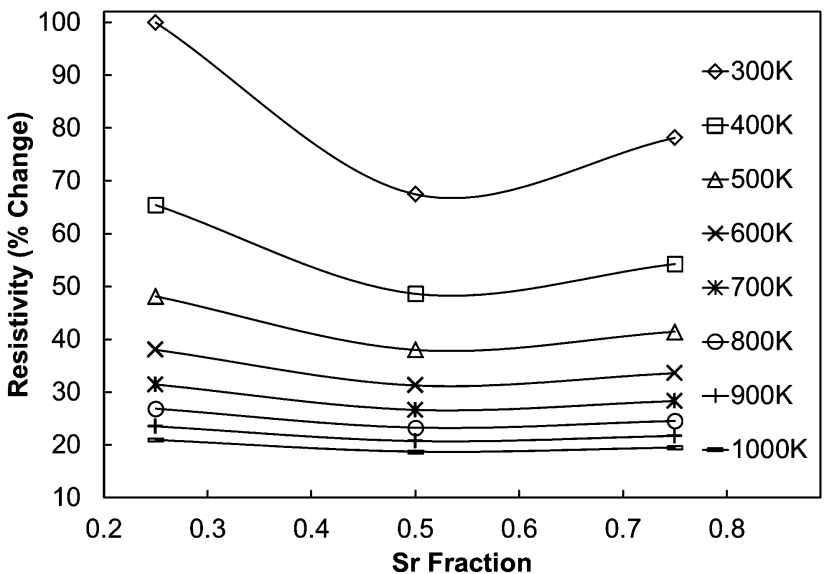

Fig. 12 Calculated percentage change in resistivity of $(\mathrm{Ca}, \mathrm{Sr}) \mathrm{MnO}_{3}$ samples with respect to $\mathrm{C} 75 \mathrm{~S} 25 \mathrm{MO}$, which shows the highest resistivity at room temperature according to DFT calculations.

unavoidable intrinsic defects in perovskite materials. ${ }^{20}$ As noted previously, Mo doping will have a similar effect as $V_{\mathrm{o}}$ doping, as both defects have been shown to have the effect of increasing the concentration of $\mathrm{Mn}^{3+}$. Consequently, an increase of Mo in the experimental samples leads to a reduction in resistivity, with resistivity of C9S1MM2 greater than that of C9S1MM4.

The experimental Seebeck coefficient data are presented in Fig. 13. All Seebeck coefficients are negative, indicating n-type conduction, and increase uniformly with increasing temperature. At low temperatures, the values are smaller than those reported by $\mathrm{Xu}$ et al. ${ }^{15}$ for undoped $\mathrm{CaMnO}_{3}$ (Fig. 13). Increasing Sr substitution for Ca reduced the Seebeck coefficients, but the materials still exhibited moderate values of -90 to $-190 \mu \mathrm{V} \mathrm{K}^{-1}$ at $1000 \mathrm{~K}$. The highest Seebeck coefficient was obtained for C9S1MM2 which contained $2 \mathrm{~mol} \% \mathrm{Mo}$; further increase in the Mo content led to a reduction in the Seebeck coefficient as a result of changes in carrier concentration. These trends are in agreement with our DFT calculations (Fig. 14). In particular, the calculations showed a reduction of the Seebeck coefficient

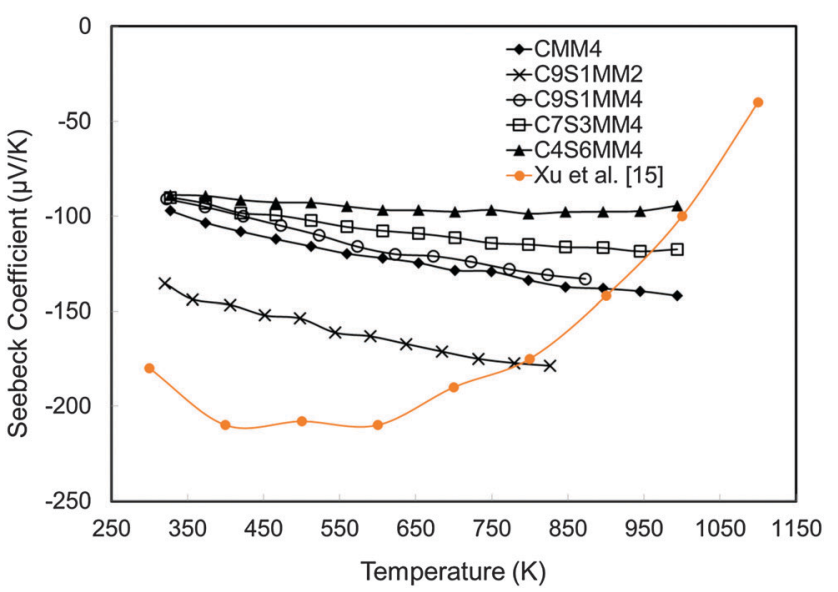

Fig. 13 Experimentally determined Seebeck coefficients of Sr-Mo substituted $\mathrm{CaMnO}_{3}$ as a function of temperature. 

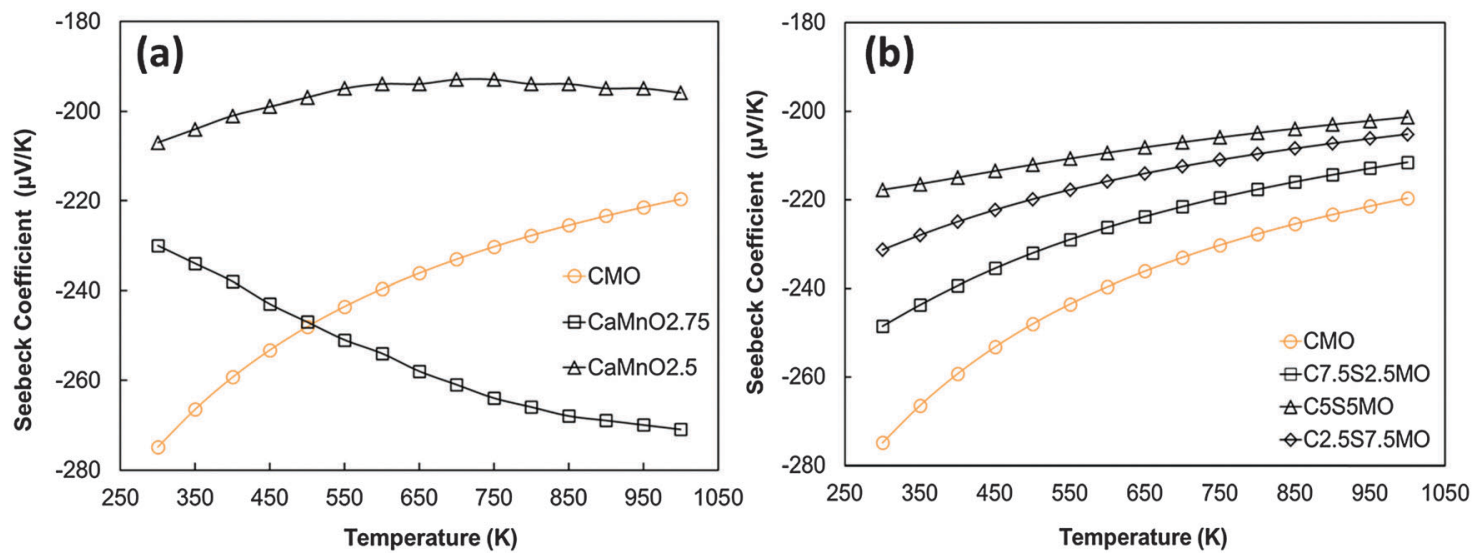

Fig. 14 Calculated temperature dependence of Seebeck coefficient of (a) defective $\mathrm{CaMnO}_{3-\delta}$ (redrawn from Molinari et al. ${ }^{23}$ ) and (b) Sr substituted $\mathrm{CaMnO}_{3}$.

(i) with the increasing concentration of $\mathrm{Mn}^{3+23}$ (Fig. 14a), and (ii) with the increasing Sr content - the highest values are found for samples with the lowest Sr content (Fig. 14b). Our data also show that intermediate doping levels do not improve the Seebeck coefficients, while high (75\%) and low (25\%) Sr substitutions do. The calculated temperature dependence for the Seebeck coefficient of Sr substituted samples, as well as for stoichiometric $\mathrm{CaMnO}_{3}$, show a decrease in the value with increasing temperature, while the oxygen sub-stoichiometric samples show different trends (Fig. 14a and b) more in line with experimental findings. It is clear that changes in the measured Seebeck coefficients arise from the complex experimental structure and thus our DFT data can be used as a guideline to disentangle the effects of $\mathrm{Sr}$ and $\mathrm{Mn}^{3+}$ doping.

It has been shown that in complex mixed $\mathrm{Mn}^{3+} / \mathrm{Mn}^{4+}$ manganates, such as these, Jahn-Teller distortions (JT) can have an impact on the Seebeck coefficient ${ }^{56-58}$ and should therefore be considered. The Seebeck coefficient $(S)$ may be calculated using the Heikes formula ${ }^{56}$ involving only the electronic degeneracy of $\mathrm{Mn}^{3+}$ and $\mathrm{Mn}^{4+}$ species and the molar fraction:

$$
S=-\frac{k_{\mathrm{B}}}{e} \ln \left(\frac{g_{\mathrm{Mn}^{4+}}}{g_{\mathrm{Mn}^{3+}}}\left(\frac{x_{\mathrm{Mn}^{4+}}}{x_{\mathrm{Mn}^{3+}}}\right)\right)
$$

where $k_{\mathrm{B}}$ is the Boltzmann constant, $e$ is the electronic charge, $x$ is the molar fraction of the species, and $g_{\mathrm{Mn}^{3+}}$ and $g_{\mathrm{Mn}^{4+}}$ are the electronic degeneracy of the electron donor $\mathrm{Mn}^{3+}$ and the electron acceptor $\mathrm{Mn}^{4+}$ (their values will depend on the spin and JT distortion). The ratio between the molar fraction of $\mathrm{Mn}^{4+}$ (number of available sites for hopping charges) and $\mathrm{Mn}^{3+}$ does not account for the molar faction of octahedral environments occupied by $\mathrm{Mo}^{6+}$ as these sites are not available for electron hopping. We have assumed that $x_{\mathrm{Mn}^{3+}}$ is double $x_{\mathrm{Mo}^{6+}}$ as each $\mathrm{Mo}^{6+}$ injects two electrons in the system. By considering electronic degeneracy (product of spin and orbital degeneracy) for $\mathrm{Mn}^{4+}, \mathrm{Mn}^{3+}$, and $\mathrm{Mn}^{3+}$ with Jahn-Teller (JT) distortion (degenerate $t_{2 g}$ orbitals and split $e_{g}$ orbitals), for appropriate high spin (HS) and low spin (LS) configurations, we have calculated the Seebeck coefficients for experimental formulations using the Heikes formula. The results are presented in Table 7.

Comparing the extrapolated experimental values from the region of low $T$ with the expected high temperature limit of the Seebeck coefficients according to the Heikes formula, we would expect that the $\mathrm{Mn}^{3+}$ ions should be in the low or high spin states and there is no evidence for Jahn-Teller distortion. Similarly, comparing the extrapolated experimental values from the region of high $T$ with the expected high temperature limit of the Seebeck coefficients according to the Heikes formula, we would expect that only samples that do not contain Sr substitution on the A site will contain $\mathrm{Mn}^{3+}$ ions with Jahn-Teller distortion, while samples containing Sr substitution do not (with the exception of C9S1MM4). An effect on the Seebeck coefficient due to $\mathrm{Sr}$ substitution was indeed determined by using DFT calculations, where we found a reduction of the Seebeck coefficient with increasing $\mathrm{Sr}$ content, also in agreement with the values of $S_{\text {Expt }}$. in Table 7.

Table 7 Seebeck coefficient calculated using the Heikes $\left(S_{H}\right)$ formula considering $\mathrm{Mn}^{4+}$ always in a HS state and $\mathrm{Mn}^{3+}$ in LS, HS and JT. The $S_{\text {Expt }}: T \rightarrow \infty$ (low $T$ ) was calculated from the experimentally measured values of the Seebeck coefficient, extrapolated to infinite $T$ including only values below $500 \mathrm{~K}$ as in this region the electrical conductivity is relatively low. The $S_{\text {Expt }}: T \rightarrow \infty$ (high $T$ ) was calculated from the experimentally measured values of the Seebeck coefficient, extrapolated to infinite temperature including only values above $700 \mathrm{~K}$ (Extrapolated values taken from $S$ values in Fig. 13.)

\begin{tabular}{|c|c|c|c|c|c|}
\hline Formulation & $\begin{array}{l}S_{\mathrm{H}}\left(\mu \mathrm{V} \mathrm{K}{ }^{-1}\right) \\
\left(\mathrm{Mn}^{4+}, \mathrm{HS} / \mathrm{Mn}^{3+}, \mathrm{LS}\right)\end{array}$ & $\begin{array}{l}S_{\mathrm{H}}\left(\mu \mathrm{V} \mathrm{K} \mathrm{K}^{-1}\right) \\
\left(\mathrm{Mn}^{4+}, \mathrm{HS} / \mathrm{Mn}^{3+}, \mathrm{HS}\right)\end{array}$ & $\begin{array}{l}S_{\mathrm{H}}\left(\mu \mathrm{V} \mathrm{K} \mathrm{K}^{-1}\right) \\
\left(\mathrm{Mn}^{4+}, \mathrm{HS} / \mathrm{Mn}^{3+}, \mathrm{JT}\right)\end{array}$ & $\begin{array}{l}S_{\text {Expt }}\left(\mu \mathrm{V} \mathrm{K} \mathrm{K}^{-1}\right) \\
T \rightarrow \infty \text { high } T\end{array}$ & $\begin{array}{l}S_{\text {Expt }}\left(\mu \mathrm{V} \mathrm{K} \mathrm{K}^{-1}\right) \\
T \rightarrow \infty \text { low } T\end{array}$ \\
\hline $\mathrm{CaMn}_{0.96} \mathrm{Mo}_{0.04} \mathrm{O}_{3}$ & -137 & -128 & -187 & -175 & -147 \\
\hline $\mathrm{Ca}_{0.9} \mathrm{Sr}_{0.1} \mathrm{Mn}_{0.98} \mathrm{Mo}_{0.02} \mathrm{O}_{3}$ & -202 & -193 & -253 & -210 & -188 \\
\hline $\mathrm{Ca}_{0.7} \mathrm{Sr}_{0.3} \mathrm{Mn}_{0.96} \mathrm{Mo}_{0.04} \mathrm{O}_{3}$ & -137 & -128 & -187 & -134 & -124 \\
\hline $\mathrm{Ca}_{0.4} \mathrm{Sr}_{0.6} \mathrm{Mn}_{0.96} \mathrm{Mo}_{0.04} \mathrm{O}_{3}$ & -137 & -128 & -187 & -92 & -102 \\
\hline
\end{tabular}



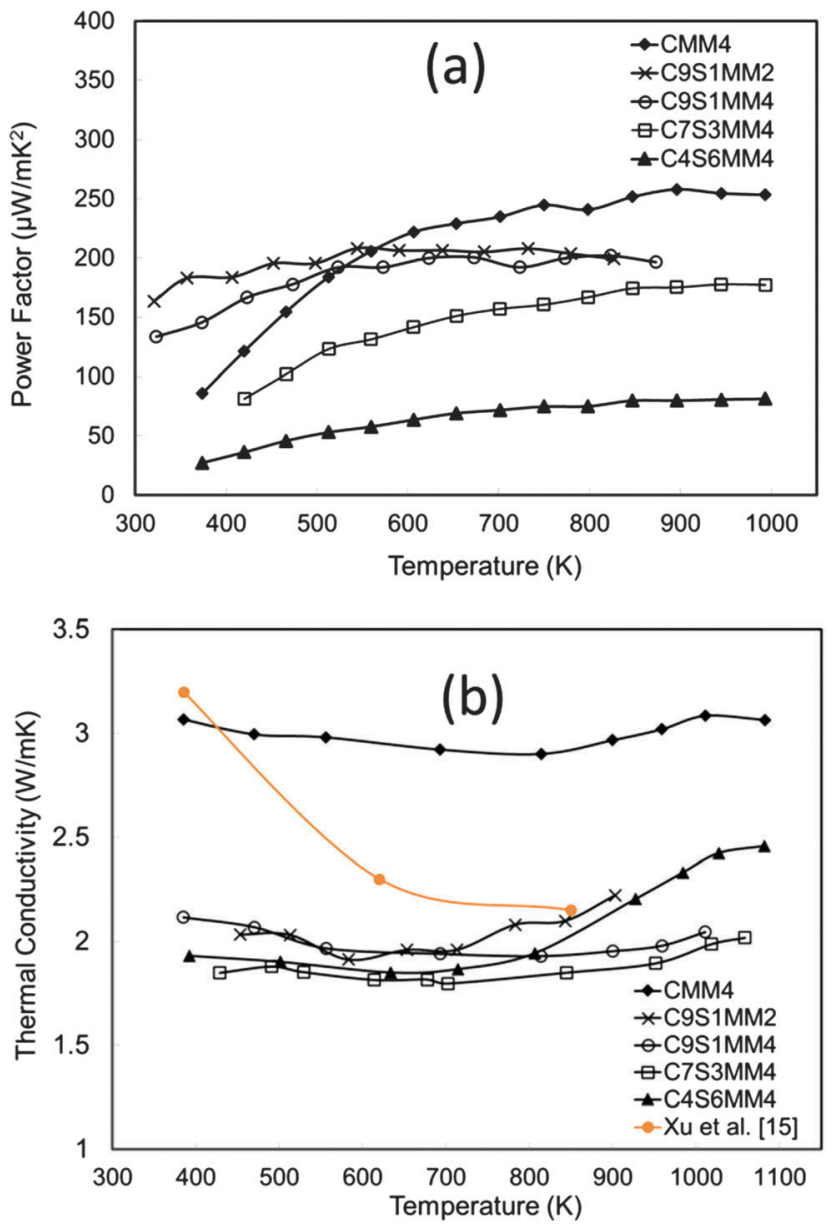

Fig. 15 (a) Temperature dependence of the experimental power factor of $\mathrm{Sr}-\mathrm{Mo}$ substituted $\mathrm{CaMnO}_{3}$, (b) temperature dependence of thermal conductivity of $\mathrm{Sr}-\mathrm{Mo}$ substituted $\mathrm{CaMnO}_{3}$.

Structural data can also be used to detect the presence of Jahn-Teller distortion. Calculated $\mathrm{Mn}-\mathrm{O}$ distances (from the experimental data, Table 5) differ by less than $0.007 \AA$ Å between $\mathrm{Mn}-\mathrm{O}_{\mathrm{eq}}$ and $\mathrm{Mn}-\mathrm{O}_{\mathrm{ap}}$ for all samples with the exception of C9S1MM4 and CMM4 where the differences are 0.02 and $0.01 \AA$, respectively. Whether these differences are meaningful is debatable as the experimental samples are polycrystalline. However, DFT calculations do support the proposal of Jahn-Teller distortion in octahedral sites containing $\mathrm{Mn}^{3+}$, but not in octahedral sites containing $\mathrm{Mn}^{4+}$. Thus, it is not possible to rule out the presence of Jahn-Teller distortion from the experimental data but we support its presence from the computational data.

The power factor data are presented in Fig. 15(a). The power factor values are in the range reported for both A-site and B-site substituted $\mathrm{CaMnO}_{3} \cdot{ }^{11,12,14,18}$ It can be seen that substitution of $\mathrm{Sr}$ reduces the power factor. This is mainly due to reduction of the Seebeck coefficient as discussed in the above section.

The thermal conductivity data are presented in Fig. 15(b). Interestingly, thermal conductivity is much reduced by $\mathrm{Sr}$ doping, and the values are lower than for undoped $\mathrm{CaMnO}_{3}$ (data from $\mathrm{Xu}$ et $a l^{15}{ }^{15}$ ). The introduction of $\mathrm{Sr}$ with a larger ionic radius than $\mathrm{Ca}$ induces structural modification, reducing phonon propagation. Similar effects for A-site doped $\mathrm{CaMnO}_{3}$ have been reported by Ohtaki et al. ${ }^{14}$ and Dabrowski. ${ }^{59}$

The electronic thermal conductivity, $k_{\mathrm{el}}$, was calculated using the formula:

$$
k_{\mathrm{el}}=L_{0} T \delta
$$

where $L_{0}$ is the Lorenz factor $\left(2.44 \times 10^{-8} \mathrm{~W} \Omega \mathrm{K}^{-2}\right)$ and $\delta$ is the conductivity of the sample at temperature $T$. The calculated $k_{\mathrm{el}}$ values were significantly higher for doped samples compared to $\mathrm{CaMnO}_{3}$. This can be attributed to improved conductivity of the samples. However, even for doped samples the contributions of $k_{\mathrm{el}}$ were less than $10 \%$ of overall thermal conductivity. Hence, suppression of lattice thermal conductivity, $k_{\text {lattice }}$ can be achieved by introducing $\mathrm{A} / \mathrm{B}$ site dopants of different ionic sizes, and the presence of sub-grains/domains, and twins all lead to reduction of the total thermal conductivity $\left(k_{\text {total }}\right)$ in $\mathrm{CaMnO}_{3}$ based materials. The sample C7S3MM4 exhibits the lowest $K_{\text {total }}$ of $1.6 \mathrm{~W} \mathrm{~m}^{-1} \mathrm{~K}^{-1}$ at $1000 \mathrm{~K}$.

Whether or not $\mathrm{Sr}$ substitution reduces $k_{\text {lattice, }}$ is hard to evaluate from experimental data alone, where the sample microstructure and complex defects play important roles. Thus, our DFT calculations on single bulk crystals are crucial to determine the effect of Sr substitution on thermal transport in the perovskite structure. Our results show clearly that $\mathrm{Sr}$ substitution reduces $k_{\text {lattice }}$ compared to that in pure $\mathrm{CaMnO}_{3}$ (Fig. 16). However the trend and effect is not directly proportional to the Sr content; the lowest concentration of the dopant is more beneficial than the intermediate concentration. The calculations demonstrate that introducing $25 \%$ of a different cation on the perovskite A site, decreases $k_{\text {lattice }}$ by increasing phonon-phonon scattering.

In order to assess whether the presence of domain boundaries directly affects $k_{\text {lattice }}$ we used molecular dynamics, which enabled us to use large simulation cells. The calculated thermal conductivity of $\mathrm{CaMnO}_{3}$ containing two domain boundaries spaced $7.5 \mathrm{~nm}$ apart was found to be reduced by approximately $7 \%$ compared to the stoichiometric single crystal. This reduction

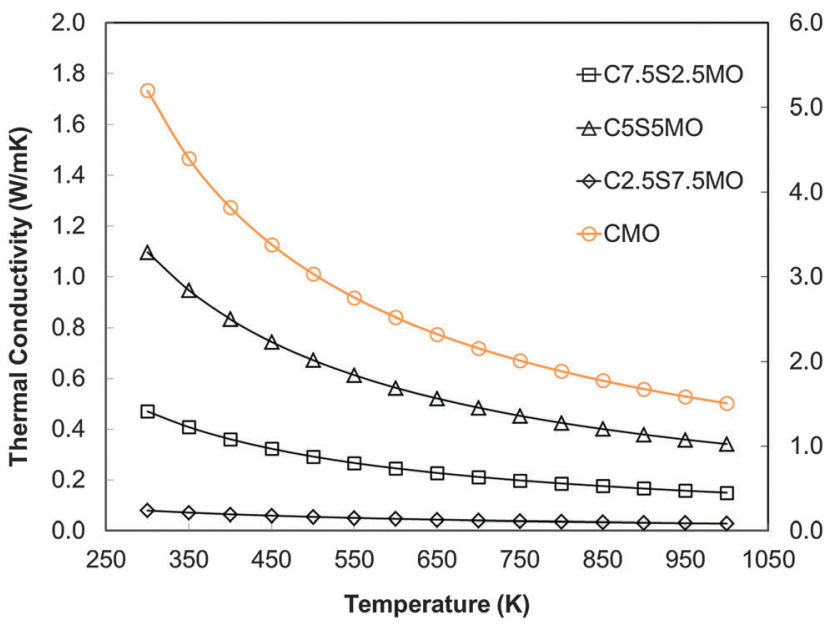

Fig. 16 Calculated temperature dependence of lattice thermal conductivity ( $k_{\text {lattice }}$ ) of $\mathrm{Sr}$ substituted $\mathrm{CaMnO}_{3}$. 


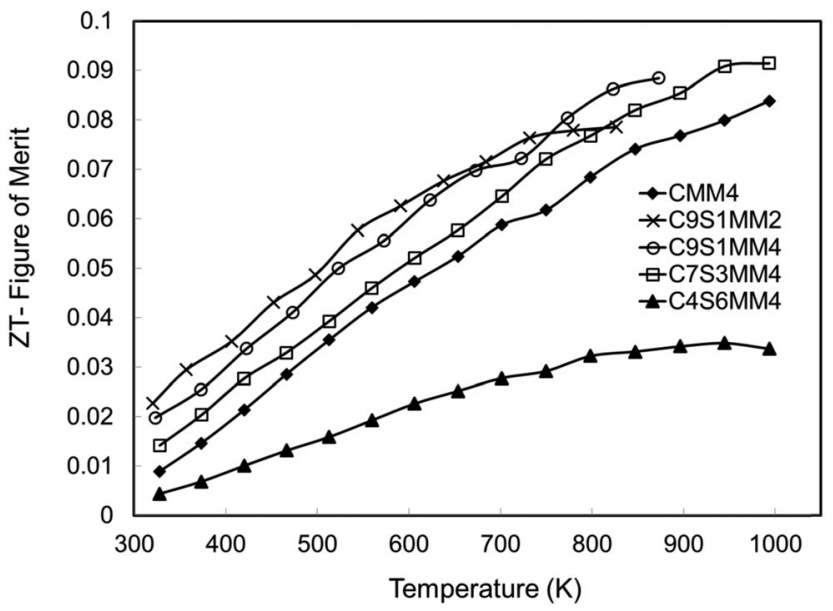

Fig. $17 Z T$ values for $\mathrm{Sr}-\mathrm{Mo}$ substituted $\mathrm{CaMnO}_{3}$

is clearly dependent on the concentration of these domain boundaries and their distance apart. A detailed computational quantitative evaluation of the impact of domain boundaries and related structural features on $k_{\text {lattice }}$ would therefore be very valuable but it is beyond the scope of this paper.

The $Z T$ data are presented in Fig. 17. Consistent with other investigations of $\mathrm{CaMnO}_{3}$ based materials, ${ }^{15,16,18}$ the $Z T$ values increase almost linearly with temperature. Whilst the samples rich in $\mathrm{Sr}$ and Mo (C4S6MM4) exhibit the lowest $Z T$ values, the data for the other samples are clustered together (Fig. 17), with C9S1MM2 having significantly higher values up to $800 \mathrm{~K}$. The superior properties of C9S1MM2 arise from the combination of lower resistivity (Fig. 11) and higher Seebeck coefficients (Fig. 13). The addition of Mo to the perovskite is beneficial to the thermoelectric performance because of the generation of $\mathrm{Mn}^{3+}$ and additional carriers. Whilst the $Z T$ values for Mo-added $\mathrm{CaMnO}_{3}$ (CMM4) are much superior to those of undoped $\mathrm{CaMnO}_{3}$, the best properties were obtained for materials containing modest amounts of both $\mathrm{Sr}$ (on the A-site), and an optimum addition of Mo ( $2 \mathrm{~mol} \%)$. Higher levels of Mo led to a reduction in the Seebeck coefficient and thereby the power factor and $Z T$.

The thermoelectric properties of $\mathrm{CaMnO}_{3}$-based ceramics depend critically on the changes in the composition, structure and transport behaviour as demonstrated by high resolution electron microscopy and modelling. Substitution of Sr stabilises the tetragonal form of $\mathrm{CaMnO}_{3}$; atomically resolved imaging and analysis showed a random distribution of $\mathrm{Sr}$ in the A-site of the perovskite structure and revealed a boundary structure of $90^{\circ}$ rotational twin boundaries across $\{101\}_{\text {orthorhombic; }}$ the latter are predominant phonon scattering sources to lower the thermal conductivity as suggested by potential based calculations. Simultaneous HAADF and BF images provided experimental evidence for changes in the oxygen positions for the two [101] $]_{\text {ortho }}$ and $[-101]_{\text {ortho }}$ planes. Substitution of Mo on the B site leads to the generation of additional carriers due to the presence of $\mathrm{Mn}^{3+}$ in the $\mathrm{Mn}^{4+}$ matrix. This reduces electrical resistivity, but excess amounts of Mo also reduced the Seebeck coefficients.
Introducing $\mathrm{A} / \mathrm{B}$ site dopants of different ionic sizes increased phonon scattering, thereby reducing thermal conductivity. The different types of sub-grain structure (wavy and straight sub-grain boundaries) domains boundaries and twins (revealed by electron microscopy) also help to reduce thermal conductivity. The importance of such features was highlighted by potential based molecular dynamics that showed the presence of two domain boundaries spaced $7.5 \mathrm{~nm}$ apart in $\mathrm{CaMnO}_{3}$ could reduce the thermal conductivity by approximately $7 \%$ compared to the stoichiometric single crystal. Ceramics of $\mathrm{Ca}_{0.7} \mathrm{Sr}_{0.3} \mathrm{Mn}_{0.96} \mathrm{Mo}_{0.04} \mathrm{O}_{3}$ exhibit enhanced properties with $S_{1000 \mathrm{~K}}=-180 \mu \mathrm{V} \mathrm{K}^{-1}, \rho_{1000 \mathrm{~K}}=$ $5 \times 10^{-5} \Omega \mathrm{m}, k_{1000 \mathrm{~K}}=1.8 \mathrm{~W} \mathrm{~m}^{-1} \mathrm{~K}^{-1}$ and $Z T \approx 0.11$ at $1000 \mathrm{~K}$.

\section{Conclusions}

High quality, crack-free $\mathrm{CaMnO}_{3}$-based ceramics, with densities greater than $90 \%$ theoretical, were produced by addition of $\mathrm{Sr}$, and slow cooling rates after sintering. Substitution of Ca by $\mathrm{Sr}$ in $\mathrm{CaMnO}_{3}$ changes the symmetry from orthorhombic (Pnma) to tetragonal $(14 / \mathrm{mcm})$; the larger Sr ions stabilise the tetragonal structure by broadening the structural transition window, thereby improving material stability.

Cooling from the high temperature cubic form during sintering gives rise to sub-grain boundaries within the grains which are predominantly wavy in Sr-poor (orthorhombic symmetry) materials, and straight in the Sr-rich (tetragonal symmetry) ceramics.

There was no evidence of $\mathrm{Sr}$ and $\mathrm{Ca}$ ordering in the A-site of the perovskite structure, but atomic resolution microscopy suggested that differences in bright field images are related to changes in the oxygen positions for the two [101 $]_{\text {ortho }}$ and $[-101]_{\text {ortho }}$ planes. Modelling supported the experimental findings that there was no lateral displacement of A-site and B-site columns.

The presence of Mo in the initial powder formulation is beneficial for processing, but its incorporation in the final ceramic increases the concentration of electronic carriers, improving thermoelectric properties. DFT calculations demonstrated that the Fermi level was dominated by $\mathrm{Mn}^{3+}$ and $\mathrm{O}^{2-}$ states upon Mo substitution. Furthermore, DFT calculations supported the presence of Jahn-Teller distortion of octahedral sites containing $\mathrm{Mn}^{3+}$.

Electrical resistivity values for the Mo doped samples are amongst the lowest reported for B-site doped $\mathrm{CaMnO}_{3}$. This arises from the creation of additional charge carriers due to the presence of $\mathrm{Mn}^{3+}$ in the $\mathrm{Mn}^{4+}$ matrix. The higher resistivity in the Sr-Mo doped samples appears to be related to the disordered distribution of $\mathrm{Ca}$ and $\mathrm{Sr}$ on A sites, and possibly the arrangement of oxygen vacancies.

High levels of $\mathrm{Sr}$ and Mo were detrimental to the Seebeck coefficient, as a result of changes in carrier concentrations, as confirmed by DFT calculations. However, substituting $\mathrm{Sr}$ for $\mathrm{Ca}$ in $\mathrm{CaMnO}_{3}$ causes structural modifications, and the presence of A/B site dopants of different ionic sizes, and the existence of sub-grains/domains, and twins leads to a reduction in the total 
thermal conductivity. DFT calculations show that Sr substitution reduces $k_{\text {lattice }}$ compared to that in pure $\mathrm{CaMnO}_{3}$, while potential based molecular dynamics calculations showed that the presence of two close domain boundaries will have a significant impact on phonon transport, reducing thermal conductivity.

\section{Acknowledgements}

We acknowledge the EPSRC for funding EP/I036230/X, EPJ000620/1, $\mathrm{EP} / \mathrm{I03601X/1}$ and EP/K016288/1. Computations were run on HPC ARCHER facility through the Materials Chemistry Consortium funded by EPSRC (EP/L000202) and on the HPC Aquila at the University of Bath. The SuperSTEM Laboratory is the National Facility for Aberration-Corrected STEM, supported by the EPSRC.

\section{References}

1 D. M. Rowe, Renewable Energy, 1999, 16, 1251-1256.

2 I. Terasaki, Y. Sasago and K. Uchinokura, Phys. Rev. B: Condens. Matter Mater. Phys., 1997, 56, 12685-12687.

3 R. Funahashi, I. Matsubara and S. Sodeoka, Appl. Phys. Lett., 2000, 76, 2385-2387.

4 G. J. Xu, R. Funahashi, M. Shikano, I. Matsubara and Y. Q. Zhou, Appl. Phys. Lett., 2002, 80, 3760-3762.

5 A. C. Masset, C. Michel, A. Maignan, M. Hervieu, O. Toulemonde, F. Studer, B. Raveau and J. Hejtmanek, Phys. Rev. B: Condens. Matter Mater. Phys., 2000, 62, 166-175.

6 J. He, Y. F. Liu and R. Funahashi, J. Mater. Res., 2011, 26, 1762-1772.

7 K. Koumoto, R. Funahashi, E. Guilmeau, Y. Miyazaki, A. Weidenkaff, Y. Wang and C. Wan, J. Am. Ceram. Soc., 2013, 96, 1-23.

8 K. R. Poeppelmeier, J. Solid State Chem., 1982, 45, 71-79.

9 E. S. Bozin, A. Sartbaeva, H. Zheng, S. A. Wells, J. F. Mitchell, Th. Proffen, M. F. Thrope and S. J. L. Billinge, J. Phys. Chem. Solids, 2008, 69, 2146-2150.

10 H. Taguchi, M. Nagao, T. Sato and M. Shimada, J. Solid State Chem., 1989, 78, 312-315.

11 L. Bocher, M. H. Aguirre, R. Robert, D. Logvinovich, S. Bakardjieva, J. Hejtmanek and A. Weidenkaff, Acta Mater., 2009, 57, 5667-5680.

12 R. Funahashi, N. Hosuga, N. Miyasou, E. Takeuchi, S. Urata, K. Lee, H. Ohta and K. Koumoto, Proceeding ICT 07: Twentysixth International Conference on Thermoelectrics, 2008, pp. 124-128.

13 A. Bhaskar, C.-J. Liu and J. J. Yuan, J. Electron. Mater., 2012, 41, 2338-2344.

14 M. Ohtaki, H. Koga, T. Tokunaga, K. Eguchi and H. Arai, J. Solid State Chem., 1995, 120, 105-111.

15 G. Xu, R. Funahashi, Q. Pu, B. Liu, R. Tao, G. Wang and Z. Ding, Solid State Ionics, 2004, 171, 147-151.

16 L. Bocher, H. Aguirre, D. Logvinovich, A. Shkabko, R. Robert, M. Trottmann and A. Weidenkaff, Inorg. Chem., 2008, 47, 8077-8085.
17 M. Miclau, J. Hejtmanek, R. Retoux, K. Knizek, A. Jirak, R. Fresard, A. Maignan, S. Herbert, M. Hervieu and C. Mazrtin, Chem. Mater., 2007, 19, 4243-4251.

18 P. Thiel, J. Eilertsen, S. Pupoluh, G. Sauke, M. Dobeli, A. Shabko, L. Sagarna, L. Karvonen and A. Weidenkaff, J. Appl. Phys., 2013, 114, 243707.

19 A. Reller, J. M. Thomas, D. A. Jefferson and M. K. Uppal, Proc. R. Soc. London, Ser. A, 1984, 394, 223-241.

20 A. V. Petrov, S. C. Parker and A. Reller, Phase Transitions, 1995, 55, 229-244.

21 N. N. Loshkareva and E. V. Mostovshchikova, Phys. Met. Metallogr., 2012, 113, 19-38.

22 U. Aschauer, R. Pfenninger, S. M. Selbach, T. Grande and N. A. Spaldin, Phys. Rev. B: Condens. Matter Mater. Phys., 2013, 88, 054111.

23 M. Molinari, D. A. Tompsett, S. C. Parker, F. Azough and R. Freer, J. Mater. Chem. A, 2014, 2, 14109-14117.

24 M. Schrade, R. Kabir, S. Li, T. Norby and T. G. Finstad, J. Appl. Phys., 2014, 115, 103705.

25 H. Taguchi, M. Sonoda and M. Nagao, J. Solid State Chem., 1998, 137, 82-86.

26 L. Pi, S. Herbert, C. Martin, A. Maignan and B. Raveau, Phys. Rev. B: Condens. Matter Mater. Phys., 2003, 67, 024430.

27 A. Maignan, C. Martin, C. Autret, M. Hervieu, B. Raveau and J. Hejtmanek, J. Mater. Chem., 2002, 12, 1806-1811.

28 T. Okuda and Y. Fujii, J. Appl. Phys., 2010, 108, 10372.

29 TOPAS 4.2, Bruker Corporation.

30 D. A. Tompsett, S. C. Parker, P. G. Bruce and M. S. Islam, Chem. Mater., 2013, 25, 536-541.

31 G. Kresse and J. Hafner, Phys. Rev. B: Condens. Matter Mater. Phys., 1994, 49, 14251-14269.

32 G. Kresse and J. Furthmuller, Phys. Rev. B: Condens. Matter Mater. Phys., 1996, 54, 11169-11186.

33 P. Blaha, K. Schwarz, P. Sorantin and S. B. Trickey, Comput. Phys. Commun., 1990, 59, 399-415.

34 K. Schwarz, P. Blaha and G. K. H. Madsen, Comput. Phys. Commun., 2002, 147, 71-76.

35 G. K. H. Madsen and D. J. Singh, Comput. Phys. Commun., 2006, 175, 67-71.

36 J. D. Baran, M. Molinari, N. Kulwongwit, F. Azough, R. Freer, D. Kepaptsoglou, Q. M. Ramasse and S. C. Parker, J. Phys. Chem. C, 2015, 119(38), 21818-21827.

37 D. J. Singh, Phys. Rev. B: Condens. Matter Mater. Phys., 2000, 61, 13397.

38 A. Togo, L. Chaput and I. Tanaka, Phys. Rev. B: Condens. Matter Mater. Phys., 2015, 91, 094306.

39 A. Togo, F. Oba and I. Tanaka, Phys. Rev. B: Condens. Matter Mater. Phys., 2008, 78, 134106.

40 J. M. Skelton, S. C. Parker, A. Togo, I. Tanaka and A. Walsh, Phys. Rev. B: Condens. Matter Mater. Phys., 2014, 89, 205203.

41 P. Canepa, PhD thesis, University of Kent, 2012, available from, http:/ethos.bl.uk/OrderDetails.do?did=1\&uin=uk.bl. ethos.580391.

42 G. W. Watson, E. T. Kelsey, N. H. de Leeuw, D. J. Harris and S. C. Parker, J. Chem. Soc., Faraday Trans., 1996, 92, 433-438. 
43 J. P. Allen, W. Gren, M. Molinari, C. Arrouvel, F. Maglia and S. C. Parker, Mol. Simul., 2009, 35, 584-608.

44 N. R. Williams, S. C. Parker, M. Molinari and M. T. Storr, J. Nucl. Mater., 2015, 458, 45-55.

45 S. Plimpton, J. Comput. Phys., 1995, 117, 1-19.

46 M. S. Green, J. Chem. Phys., 1954, 22, 398-413.

47 R. Kubo, J. Phys. Soc. Jpn., 1957, 12, 570-586.

48 A. J. H. McGaughey and J. M. Larkin, Annu. Rev. Heat Transfer, 2014, 17, 49-87.

49 A. J. H. McGaughey and M. Kaviany, Int. J. Heat Mass Transfer, 2004, 47, 1799-1816.

50 F. Xue, Y. Gu, L. Liang, Y. Wang and L.-Q. Chen, Phys. Rev. B: Condens. Matter Mater. Phys., 2014, 90, 220101.

51 Y. Wang and R. C. Liebermann, Phys. Chem. Miner., 1993, 20, 147-148.

52 K. Koumoto, Y. Wang, R. Zhang, A. Kosuga and R. Funahashi, Annu. Rev. Mater. Res., 2010, 40, 363-394.
53 J. H. Rask, B. A. Miner and P. R. Buseck, Ultramicroscopy, 1987, 21, 321-326.

54 M. Varela, M. P. Oxley, W. Lio, M. Watanabe, A. R. Lupini, S. T. Pantelides and S. J. Pennycook, Phys. Rev. B: Condens. Matter Mater. Phys., 2009, 79, 085117.

55 N. N. Loshkareva, N. V. Mushnikov, A. V. Korolyov, E. A. Nelfield and A. M. Balbashov, Phys. Rev. B: Condens. Matter Mater. Phys., 2008, 77, 052406.

56 W. Koshibae and S. Maekawa, Phys. Rev. Lett., 2001, 87, 236603.

57 T. D. Sparks, A. Gurlo and D. R. Clarke, J. Mater. Chem., 2012, 22, 4631.

58 P. Thiel, S. Populoh, S. Yoon, G. Saucke, K. Rubenis and A. Wiedenkaff, J. Phys. Chem. C, 2015, 119, 21860-21867.

59 B. Dabrowski, O. Chmaissem, J. Mais, S. Kolesnik, J. D. Jorgensen and S. Short, J. Solid State Chem., 2003, 170, 154-164. 